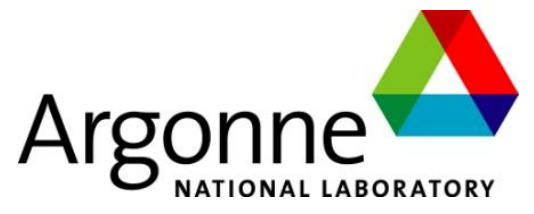

ANL/ES/RP-68384

\title{
Model Year 2010 Ford Fusion Level-1 Testing Report
}

\author{
Energy Systems Division
}




\begin{abstract}
About Argonne National Laboratory
Argonne is a U.S. Department of Energy laboratory managed by UChicago Argonne, LLC under contract DE-AC02-06CH11357. The Laboratory's main facility is outside Chicago, at 9700 South Cass Avenue, Argonne, Illinois 60439. For information about Argonne, see www.anl.gov.
\end{abstract}

\title{
Availability of This Report
}

This report is available, at no cost, at http://www.osti.gov/bridge. It is also available on paper from the U.S. Department of Energy and its contractors, for a processing fee:

U.S. Department of Energy

Office of Scientific and Technical Information

P.O. Box 62

Oak Ridge, TN 37831-0062

phone (865) 576-8401

fax (865) 576-5728

reports@adonis.osti.gov

\section{Disclaimer}

This report was prepared as an account of work sponsored by an agency of the United States Government. Neither the United States Government nor any agency thereof, nor UChicago Argonne, LLC, nor any of their employees or officers, makes any warranty, express or implied, or assumes any legal liability or responsibility for the accuracy, completeness, or usefulness of any information, apparatus, product, or process disclosed, or represents that its use would not infringe privately owned rights. Reference herein to any specific commercial product, process, or service by trade name, trademark, manufacturer, or otherwise, does not necessarily constitute or imply its endorsement, recommendation, or favoring by the United States Government or any agency thereof. The views and opinions of document authors expressed herein do not necessarily state or reflect those of the United States Government or any agency thereof, Argonne National Laboratory, or UChicago Argonne, LLC. 


\title{
Model Year 2010 Ford Fusion Level-1 Testing Report
}

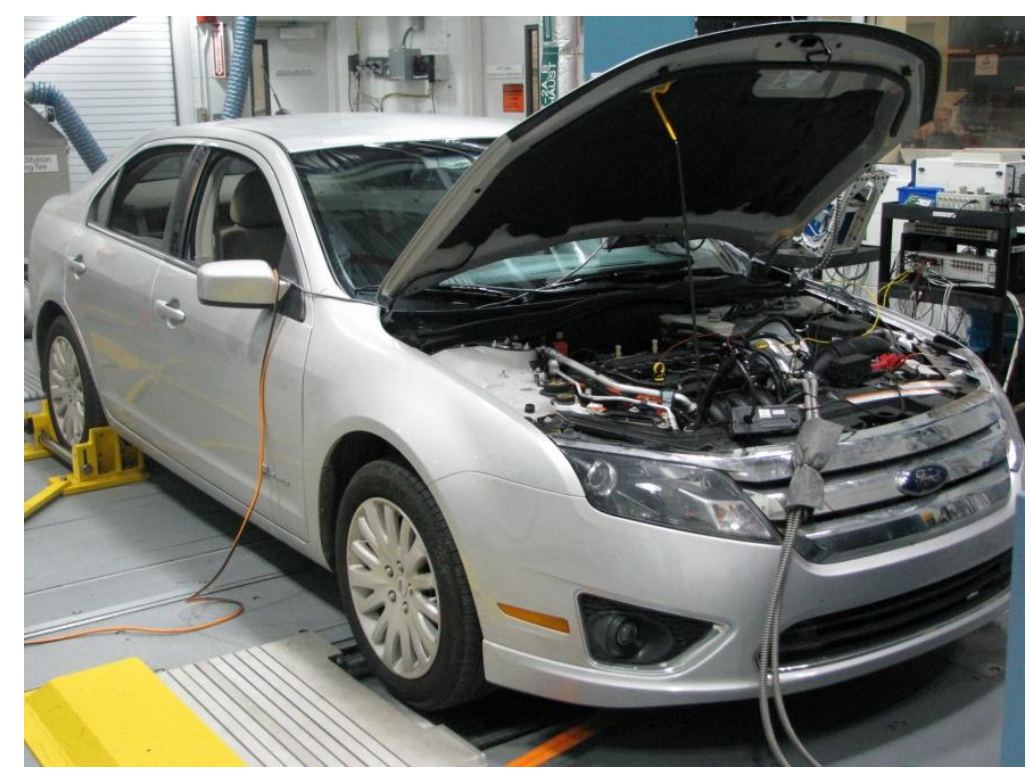

\section{$7 / 1 / 2010$}

\author{
Authors: \\ Eric Rask \\ Daniel Bocci \\ Henning Lohse-Busch \\ Michael Duoba
}
Argonne National Laboratory
9700 South Cass Avenue
Argonne, IL 60439-4815
USA




\section{Abstract}

As a part of the US Department of Energy's Advanced Vehicle Testing Activity (AVTA), a model year 2010 Ford Fusion was procured by eTec (Phoenix, AZ) and sent to ANL'S Advanced Powertrain Research Facility for the purposes of vehicle-level testing in support of the Advanced Vehicle Testing Activity. Data was acquired during testing using non-intrusive sensors, vehicle network information, and facilities equipment (emissions and dynamometer). Standard drive cycles, performance cycles, steady-state cycles, and A/C usage cycles were conducted. Much of this data is openly available for download in ANL's Downloadable Dynamometer Database

(https://webapps.anl.gov/vehicle_data/). The major results are shown in this report.

Given the benchmark nature of this assessment, the majority of the testing was done over standard regulatory cycles and sought to obtain a general overview of how the vehicle performs. These cycles include the US FTP cycle (Urban) and Highway Fuel Economy Test cycle as well as the US06, a more aggressive supplemental regulatory cycle. Data collection for this testing was kept at a fairly high level and includes emissions and fuel measurements from an exhaust emissions bench, high-voltage and accessory current/voltage from a DC power analyzer, and CAN bus data such as engine speed, engine load, and electric machine operation. The following sections will seek to explain some of the basic operating characteristics of the MY2010 Fusion and provide insight into unique features of its operation and design.

\section{Vehicle Description}

The MY2010 Ford Fusion Hybrid represents the most recent addition to Ford's hybrid lineup. The vehicle utilizes an Atkinson-cycle engine, two electric machines and a power-split device to control the allocation of energy between the electric and mechanical (fuel) power paths. As with most hybrid systems, fuel economy and emission gains are enabled through regenerative braking, engine-off at idle, electric operation at low road loads, electric assist, and the general ability to operate the engine more optimally. Notable additional operating features for this vehicle include relatively high speed engine-off operating capability ( $47 \mathrm{mph})$, improved battery/motor performance due to added voltage boosting capability, as well as improved real-world fuel economy given an electric air-conditioning system. Overall, these improvements enable the Fusion to achieve high overall fuel economy while retaining a high level of vehicle performance. 
The following are Ford Fusion vehicle specifications according to Ford Motor Company (http://www.fordvehicles.com/cars/fusion/specifications/view-all/).

\section{Gasoline Engine}

Drive Type: Front-Wheel Drive

Engine type: 2.5L Atkinson-Cycle I-4 Engine

Transmission type: Electronic Continuously Variable (eCVT)

Peak Horsepower (SAEnet@rpm): 156 HP@ 6,000

Peak Torque (lb.-ft.@rpm): 135 @ 2,250

Compression ratio: 12.3:1

Fuel delivery: Sequential Multi-Port Electronic Fuel Injection

\section{Electric Motor}

Motor type: Permanent magnet AC synchronous motor

Power output: 105 hp $(78$ kW) @ 6500 rpm

Torque: $153 \mathrm{lb} . \mathrm{ft} .(207 \mathrm{~N} \cdot \mathrm{m})$

Voltage Boosting: $130-160 \%$ claimed maximum boosting for certain conditions

\section{Traction Battery}

Type: Nickel-Metal-Hydride (NiMH)

Power Output: $35 \mathrm{hp}(26 \mathrm{~kW})$

Voltage: $275 \mathrm{~V}$

\section{Hybrid System Net Power}

$191(142 \mathrm{~kW})$

\section{Mechanical/Performance}

Front Suspension: Independent SLA with stabilizer bar

Rear Suspension: Independent Multi-link Twist Blade with Stabilizer Bar

Steering: Electric Power-Assisted

Air-conditioning: High voltage, electrically operated

\section{Vehicle}

Overall height/width/length (in): 56.8/80.1/190.6

Wheelbase(in): 107.4

Tread Width (front/rear in): 61.3/60.0

Curb weight (lb.): 3720

Seating capacity: 5

Passenger volume (cu. ft.): 99.8

Luggage capacity (cu. ft.): 11.8

Fuel tank (gal.): 17

\section{Mileage estimates}

MPG city: 41

MPG highway: 36

MPG combined: 39 


\section{Vehicle Instrumentation}

\subsection{Data Acquisition System}

Argonne's chassis dynamometer facility was specifically designed to perform vehicle and system oriented testing. With this objective in mind, a custom data acquisition and control system was built around the needs of hybrid vehicle testing. The custom design also allows integration with new measurement systems as different vehicles are tested in the lab. All data is collected from the various sources, time-aligned and merged by the Host Computer, and saved along with other test information in a $10 \mathrm{~Hz}$ data file.

\subsection{Vehicle Signals}

\begin{tabular}{|c|c|}
\hline Facility Data & Installed Sensors \\
\hline Drive Schedule [MPH] & Eng_Temp_Oil_Dipstick[C] \\
\hline Bag Number [n] & Cabin_Vent_Temp[C] \\
\hline Vehicle Speed [MPH] & Eng_FuelFlow_Direct2 [cc/s] \\
\hline Dyno_TractiveForce_Front [N] & Hioki Signals \\
\hline Dyno Front Load Cell [N] & HV Battery Voltage \\
\hline DilAir RH [\%] & HV Battery Current \\
\hline Tailpipe Pressure [in H2O] & HV Battery Power \\
\hline Cell Temp [C] & HV Battery Ahr \\
\hline Cell RH [\%] & HV Battery Whr \\
\hline Cell Press [inHg] & DC/DC-In Voltage \\
\hline Tire_Temp [C] & DC/DC-In Current \\
\hline Vehicle Network Data & DC/DC-In Power \\
\hline Batt_Temp_CAN[C] & DC/DC-In Ahr \\
\hline Batt_SOC_CAN[\%] & DC/DC-In Whr \\
\hline Wheel_Spd_FL_CAN[kph] & DC/DC-Out Voltage \\
\hline DCDC_LVCurrent_CAN[A] & DC/DC-Out Current \\
\hline DCDC_LVVoltage_CAN[V] & DC/DC-Out Power \\
\hline DCDC_HVVoltage_CAN[V] & DC/DC-Out Ahr \\
\hline Eng_Spd_CAN[rpm] & DC/DC-Out Whr \\
\hline Eng_Trq_CAN[Nm] & 12V Battery Voltage \\
\hline Whl_Trq_Req_CAN[Nm] & 12V Battery Current \\
\hline Batt_Voltage_CAN[V] & 12V Battery Power \\
\hline Batt_Current_CAN[A] & 12V Battery Ahr \\
\hline Motor_Trq_CAN[Nm] & 12V Battery Whr \\
\hline Motor_Spd_CAN[rpm] & Emissions Bench \\
\hline Gen_Trq_CAN[Nm] & $\mathrm{THC}[\mathrm{mg} / \mathrm{s}]$ \\
\hline Gen_Spd_CAN[rpm] & $\mathrm{CH} 4[\mathrm{mg} / \mathrm{s}]$ \\
\hline Trans_HVVoltage_CAN[V] & $\mathrm{NOx}[\mathrm{mg} / \mathrm{s}]$ \\
\hline Whl_Trq_Act_CAN[Nm] & COlow $[\mathrm{mg} / \mathrm{s}]$ \\
\hline Brake_TrqReq_CAN[Nm] & COmid [mg/s] \\
\hline Brake_TrqMech_CAN[Nm] & $\mathrm{CO} 2[\mathrm{mg} / \mathrm{s}]$ \\
\hline Brake_TrqRegen_CAN[Nm] & $\mathrm{HFID}[\mathrm{mg} / \mathrm{s}]$ \\
\hline & $\mathrm{NMHC}[\mathrm{mg} / \mathrm{s}]$ \\
\hline & Fuel [g/s] \\
\hline
\end{tabular}




\section{Urban Cycle Operation}

This section discusses vehicle performance over the Urban driving schedule. This schedule is meant to replicate typical stop-and-go city driving. Testing for this cycle is comprised of two repeat runs with a 10 minute soak period between repeats. The first run is referred to as "cold" due to the vehicle having no warm-up operation prior to running. The second repeat run is referred to as "warm" given the fact that the vehicle has run the cold cycle prior to running the next cycle. In addition to the overall performance over the Urban drive schedules, the difference between "hot" and "cold" operation is also of interest. Table 1 below shows the dynamometer tested, unadjusted fuel economy over both "warm" and "cold" cycles.

Table 1: Urban Fuel Economy

\begin{tabular}{|l|c|c|}
\hline & Urban Cold & Urban Warm \\
\hline Unadjusted Fuel Economy (mpg) & 45 & 49 \\
\hline
\end{tabular}

The Fusion Hybrid's Urban fuel economy is roughly an $80 \%$ improvement over the conventional Fusion's fuel economy and in fact ranks the Fusion hybrid in near the top of the EPA's Best Fuel Economy Listing. In addition to the high fuel economy values, it is worth noting that the difference between the cold and warm urban is roughly $8 \%$. This result is smaller than previous generation hybrid vehicles which typically have a difference of roughly $15 \%$.

\subsection{Engine Operation}

The reduced difference between warm and cold operation is mainly due to the Fusion's ability to enable engine-off operation fairly quickly during the "cold" cycle. Table 2 shows the fraction of engine off time for the warm and cold cycles. As would be expected given the small fuel economy difference, the difference between the fraction of engine-off time for warm and cold operation is fairly small.

Table 2: Urban Cycle Engine Off

\begin{tabular}{|l|c|c|}
\hline & Urban Cold & Urban Warm \\
\hline Engine-off Fraction of Total Time & 0.63 & 0.66 \\
\hline
\end{tabular}

As can be seen in the time-series plots of engine speed, torque, and fuel-rate in Figures 1,2 , and 3 respectively, following the first 200 seconds of cold cycle operation, the vehicle operates very similarly between the cold and warm cycles. This again speaks to the reduced "cold penalty" versus previous generations of hybrid vehicles which operate differently for a longer period of time. During the 200 second warm-up period, the vehicle can be seen to use minimal engine-off operation as opposed to the significant amount of engine-off operation observed during the warm cycle urban test. In addition to the limited engine-off operation, engine speed is also held fairly constant during the warm-up period 


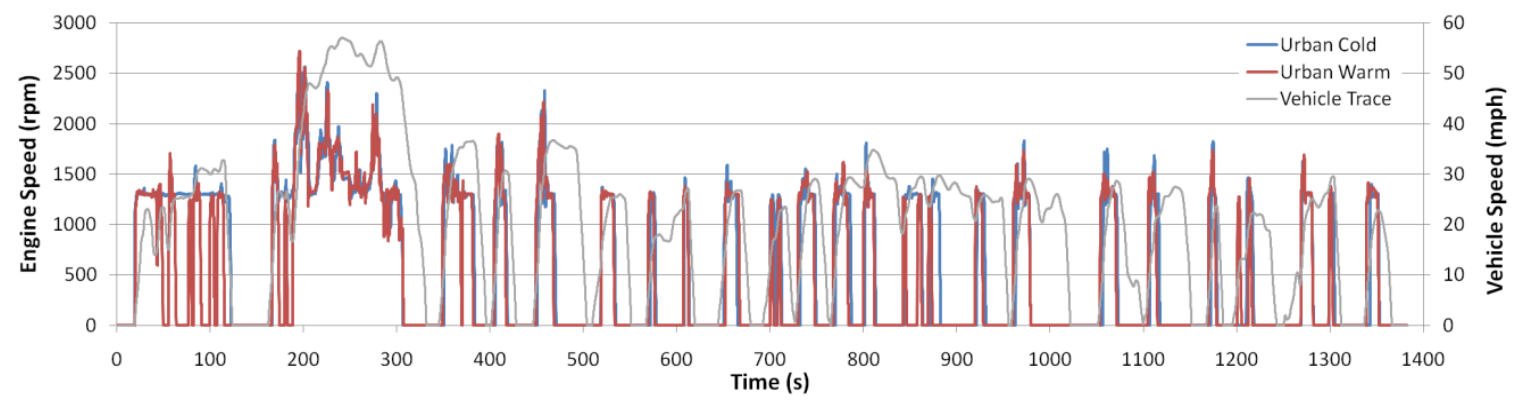

Figure 1: Urban Cycle Engine Speed

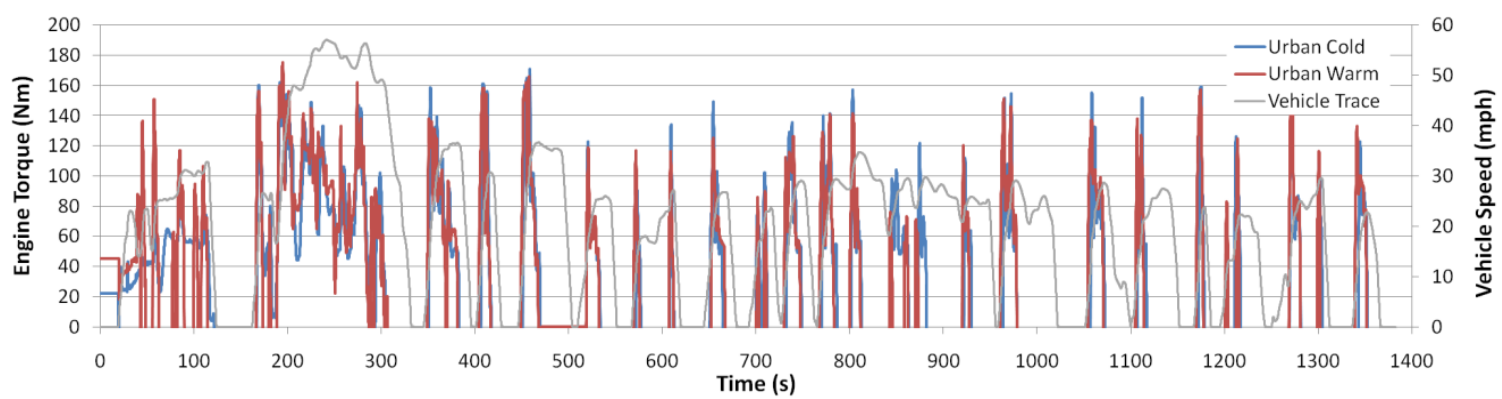

Figure 2: Urban Cycle Engine Torque

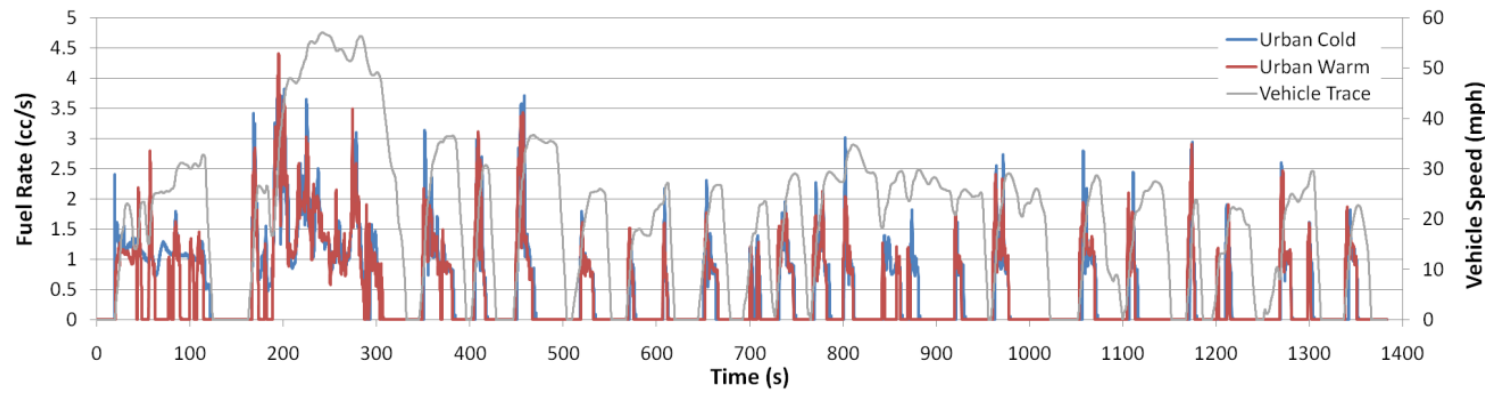

Figure 3: Urban Cycle Fuel Rate

The warm and cold cycles are also differentiated in terms of engine operating speed during the warm-up period. During this 200s period, the warm cycle appears to run the majority of engine-on operation at a slightly lower operating speed as compared to the cold cycle.

\subsection{High Voltage Battery Usage}

As with the engine usage, battery use is also similar between the warm and cold cycles aside from the first 200 seconds. As can be seen below in Table 3, the peak positive battery power (from battery to powertrain) is slightly higher during the warm cycle, while peak regenerative power (from powertrain to battery) is nearly identical. The slightly higher peak power for the warm cycle is due to a high power engine start that occurs near 200 seconds for the warm cycle, but does not occur for the cold cycle due to reduce engine-off operation during vehicle warm-up. 
Table 3: Urban Cycle Battery Peak Power

\begin{tabular}{|l|c|c|}
\hline & Urban Cold & Urban Warm \\
\hline Peak Positive Battery Power (kW) & 21.6 & 23.0 \\
\hline Peak Regen Battery Power (kW) & -23.5 & -23.5 \\
\hline
\end{tabular}

From the detailed battery usage plot in Figure 4, it can also be seen that battery usage between the cold and warm cycles is fairly similar aside from a few additional engine-off events during the initial operation of the warm cycle (first 200s).

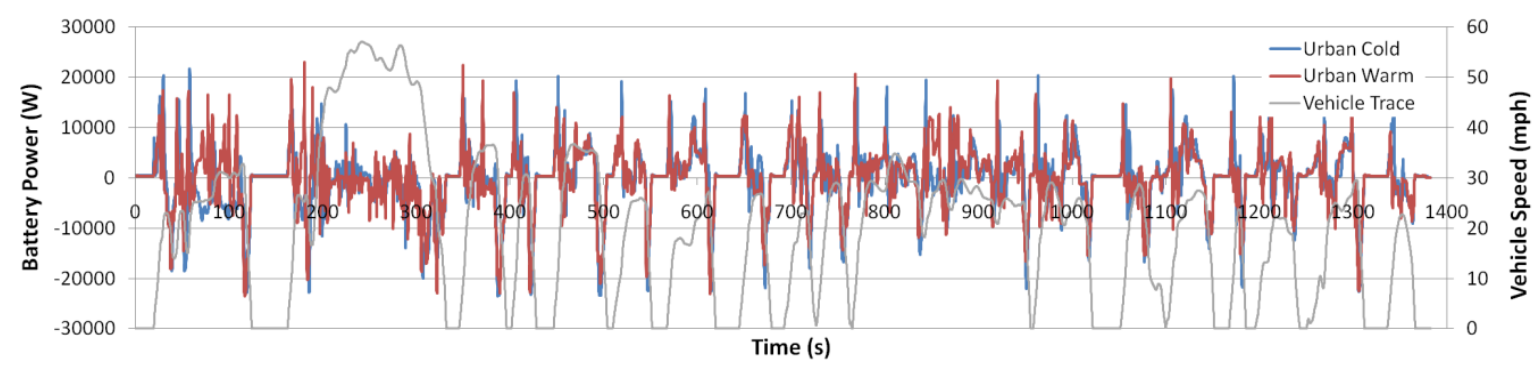

Figure 4: Urban Cycle Battery Power

In addition to measuring battery power, battery State of Charge (SOC) estimates were also taken from the vehicle data bus. Figure 5 shows the SOC versus time for the warm and cold cycles. As would be expected, battery usage during vehicle warm-up is the main point of deviation between the warm and cold cycles. From this plot, the reduced engine-off operation used in the cold cycle can be seen as an increasing SOC reading as opposed to a flat/decreasing trend indicating battery usage and thus engine-off operation. The maximum SOC swing observed over Urban cycle operation is approximately $14 \%$, which equates to a swing of roughly $0.8 \mathrm{~A}$-hr assuming a $5.5 \mathrm{~A}-\mathrm{hr}$ capacity battery pack. This swing was observed during Cold operation; the maximum swing observed during Warm operation was roughly $12 \%$.

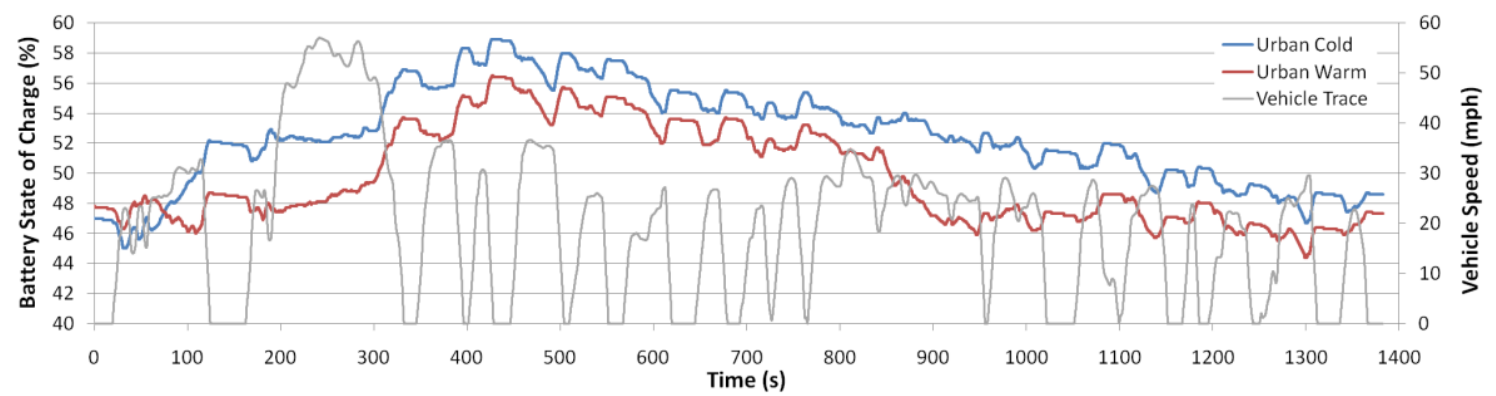

Figure 5: Urban Cycle State of Charge

\subsection{Urban Operating Strategy Discussion}

Although it can be inferred from the previous engine fueling and speed figures, Figure 6 shows a simplified version of the basic engine on/off strategy of the Fusion over the warm urban cycle. Vehicle speed is plotted and coded relative to engine on/off 
operation: orange represents engine-on operation and grey represents engine-off operation.

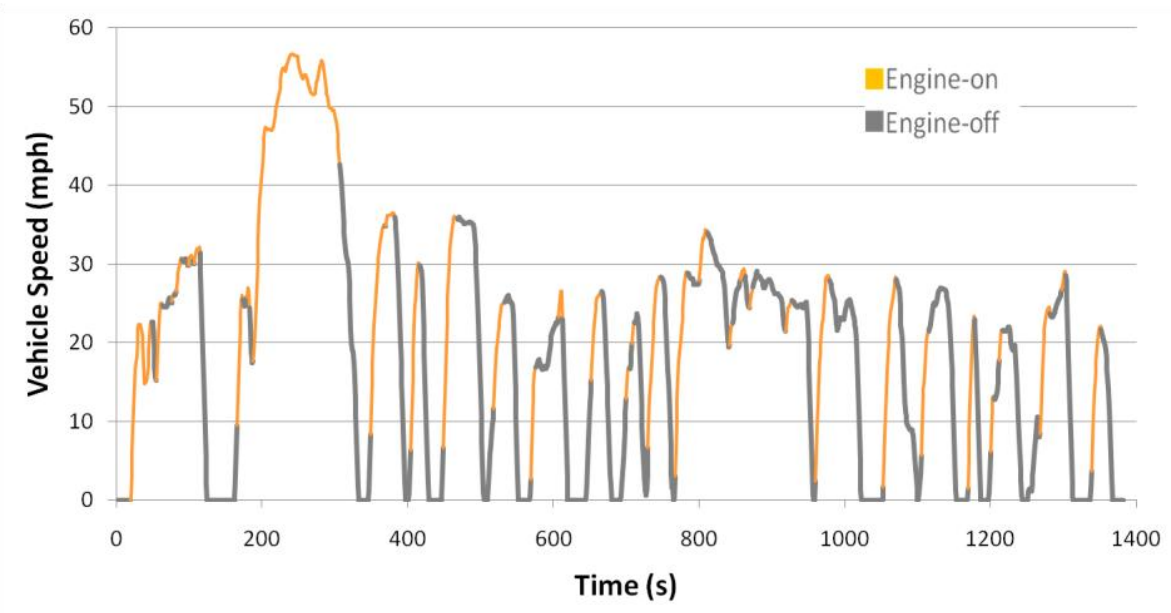

Figure 6: Warm Urban Engine On/Off Strategy Summary

\section{Highway Cycle Operation}

This section discusses vehicle operation over the Highway cycle. As its name implies, this cycle is used to evaluate higher-speed, fairly steady driving. In contrast to the Urban cycle, only the warm results for this cycle are evaluated for regulatory purposes. Table 4 shows the tested fuel economy for this cycle.

\section{Table 4: Highway Cycle Fuel Economy}

\begin{tabular}{|l|c|}
\hline & Hwy Cycle \\
\hline Unadjusted Fuel Economy (mpg) & 48 \\
\hline
\end{tabular}

\subsection{Engine Operation}

As would be expected given the Fusion's fairly large engine displacement of $2.5 \mathrm{~L}$, engine speed during moderate speed, moderate load operation is fairly low.

Furthermore, at elevated vehicle speeds, engine-off operation is limited and represents roughly $12 \%$ of the total Highway Cycle operating time. To demonstrate these issues, Figure 7 shows a histogram of engine speed over the Highway cycle. Despite the large reduction in engine-off operation versus the Urban cycle, the Fusion's 12\% engine-off operating percentage over the Highway cycle does represent a fairly high fraction relative to other current hybrids and shows the vehicle is utilizing its higher engine-off speed capability. 


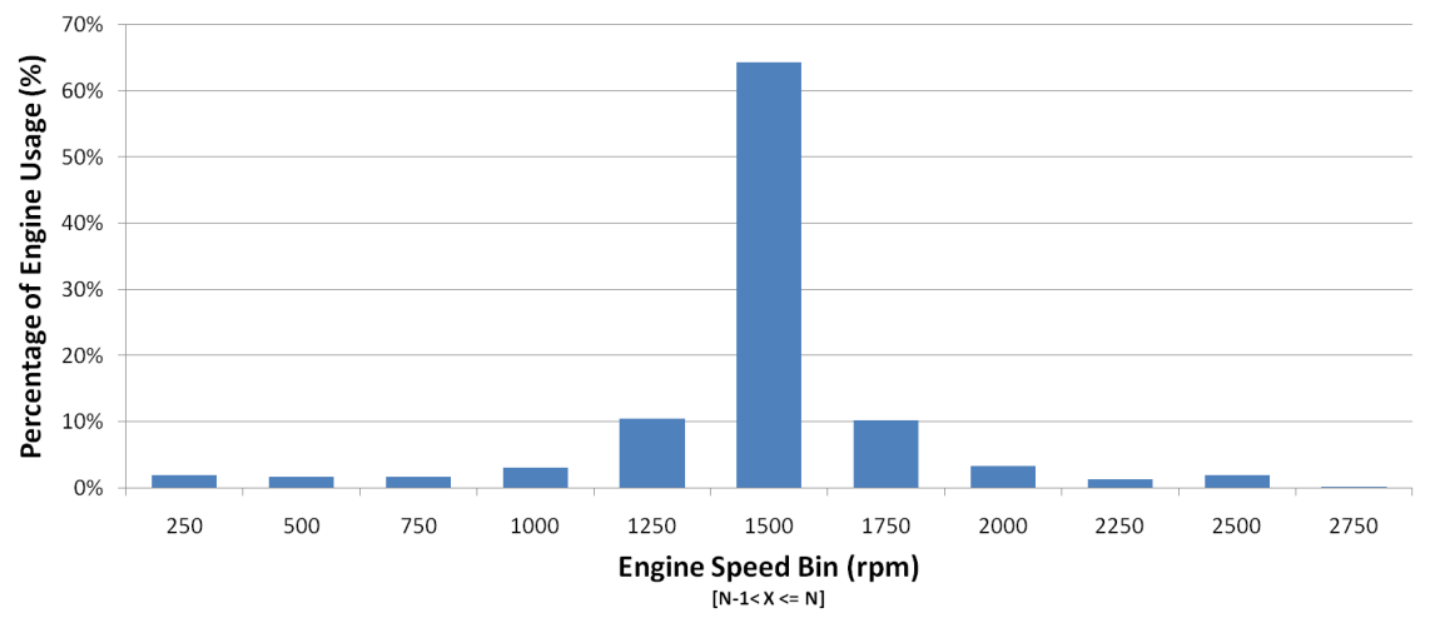

Figure 7: Highway Engine Speed Histogram

More detailed information regarding engine operation is available in the engine speed, engine torque, and fueling plots of Figures 8, 9, and 10. Again, it is notable that even during the higher speed Highway cycle, the vehicle displays significant engine-off $(R P M=0)$ operation during deceleration which enables improved regenerative braking energy capture.

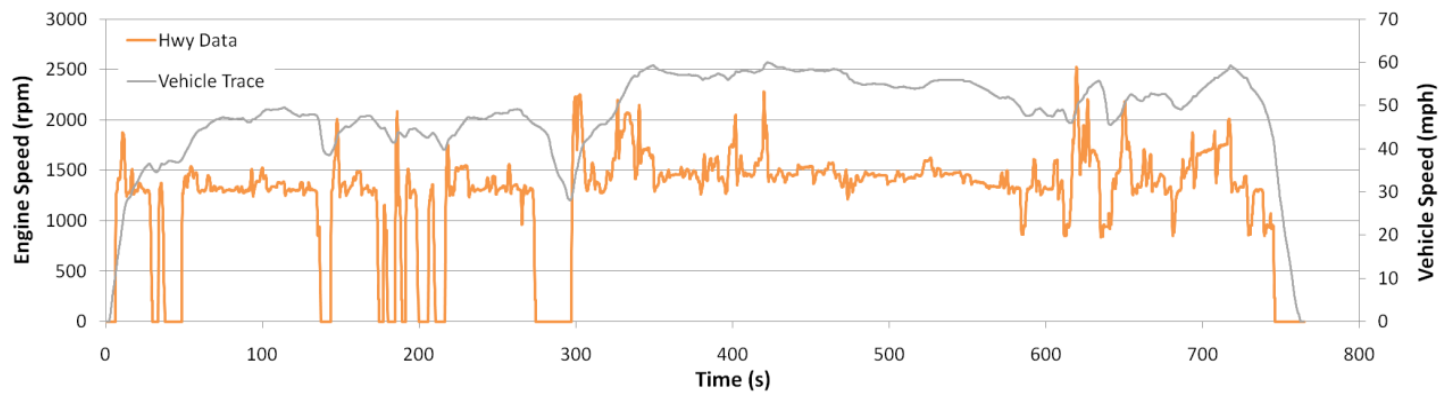

Figure 8: Highway Cycle Engine Speed

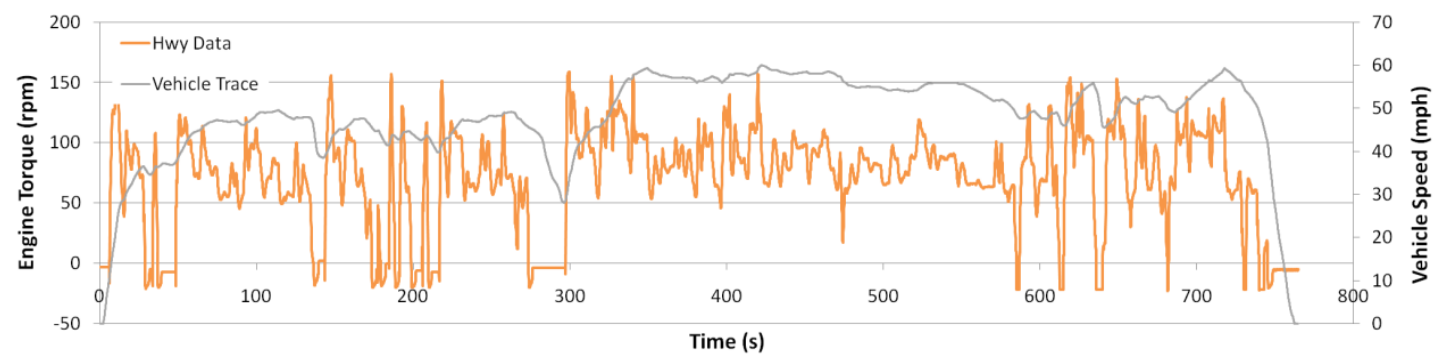

Figure 9: Highway Cycle Engine Torque 


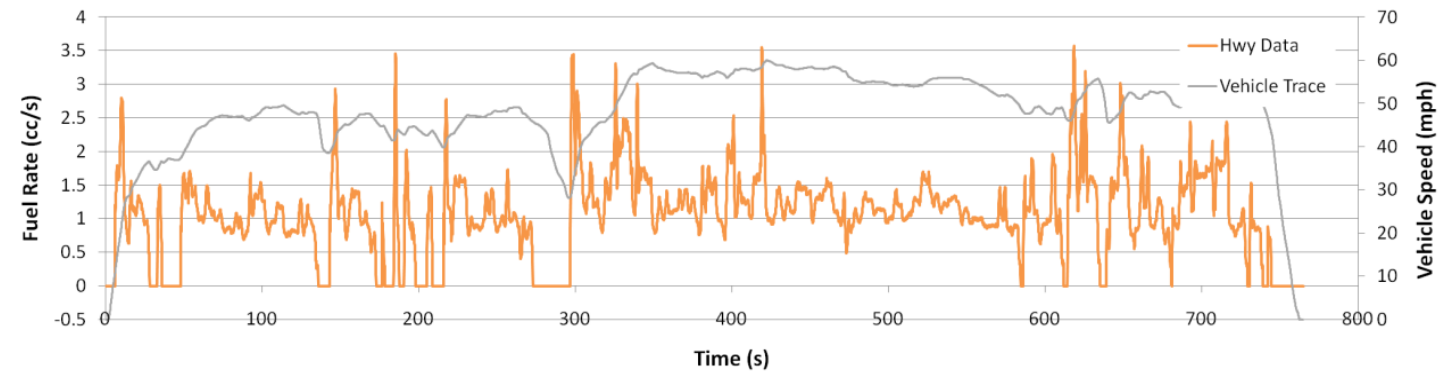

Figure 10: Highway Cycle Fuel Rate

\subsection{High Voltage Battery Usage}

During Highway operation, battery usage is fairly minimal with the engine providing the majority of the vehicle tractive power aside from a few occasions for engine restarting and torque assistance. Observed regenerative braking peak power is very similar to the Urban cycle. Table 5 shows the peak positive and negative power observed during Highway operation.

\section{Table 5: Highway Cycle Peak Battery Power}

\begin{tabular}{|l|c|}
\hline & Hwy Cycle \\
\hline Peak Positive Battery Power (kW) & 17.0 \\
\hline Peak Regen Battery Power (kW) & -24.0 \\
\hline
\end{tabular}

As with the engine data, more detailed, time-series data is provided as well. Figures 11 and 12 show the battery power and battery state-of-charge while operating over the Highway cycle, respectively. As would be expected given the diminished battery use, the maximum SOC swing observed over the Highway cycle is roughly $8 \%$ versus $14 \%$ for the Urban cycle.

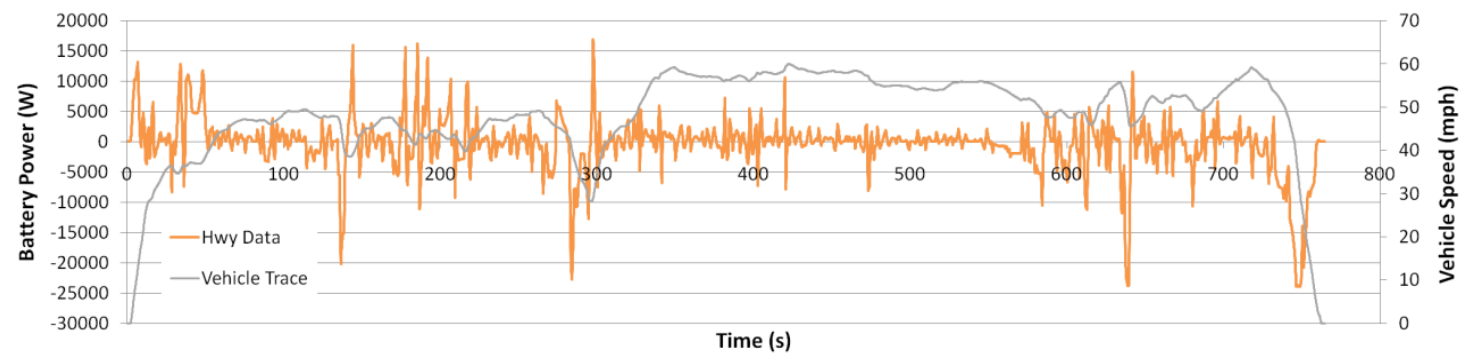

Figure 11: Highway Cycle Battery Power 


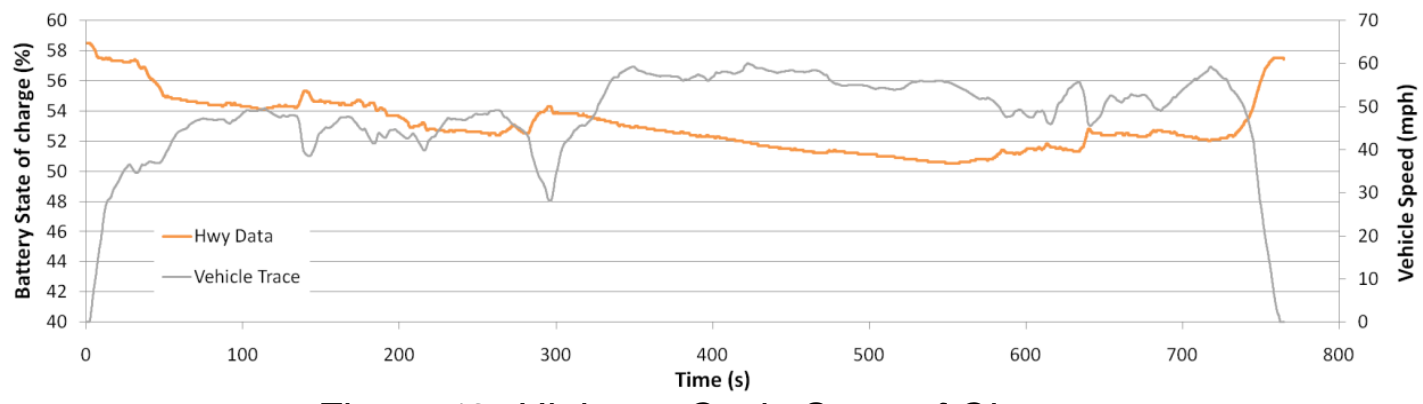

Figure 12: Highway Cycle State of Charge

\section{US06 Cycle Operation}

The final regulatory cycle used for this AVTA baseline testing is the US06 cycle. This cycle represents a mix of more aggressive stop-and-go driving and higher speed freeway type driving, at speeds generally higher than the Highway cycle. As with the Highway cycle, only the warm cycle is used for regulatory purposes. Table 6 shows the tested fuel economy over the US06 Cycle.

Table 6: US06 Fuel Economy

\begin{tabular}{|l|c|}
\hline & US06 Cycle \\
\hline Unadjusted Fuel Economy (mpg) & 33 \\
\hline
\end{tabular}

\subsection{US06 Engine Operation}

In a similar manner to the higher-speed Highway engine usage, the Fusion shows a relatively large fraction of operation in the 1250-1500 RPM operating range. However, the more aggressive driving of the US06 cycle also shows much more usage at higher engine speeds and thus power levels. Figure 13 shows the histogram of engine speed usage over the US06 cycle. Due to the stop-and-go nature of certain sections of the cycle, the vehicle also operates in engine-off mode about $20 \%$ of the total cycle time.

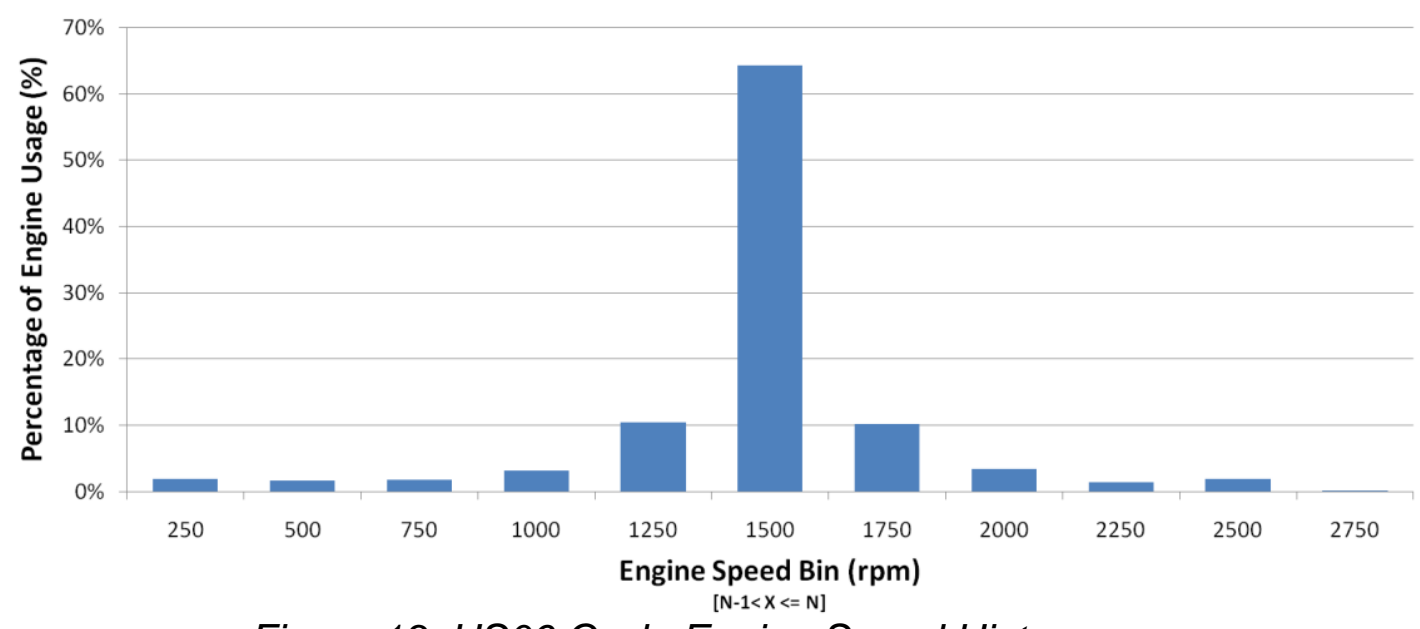

Figure 13: US06 Cycle Engine Speed Histogram 
Figures 14,15 , and 16 show more detailed information regarding engine speed, engine torque, and fueling over the US06 cycle. As can be expected with the more aggressive operation, engine speed, torque, and fueling show a much greater range of operation.

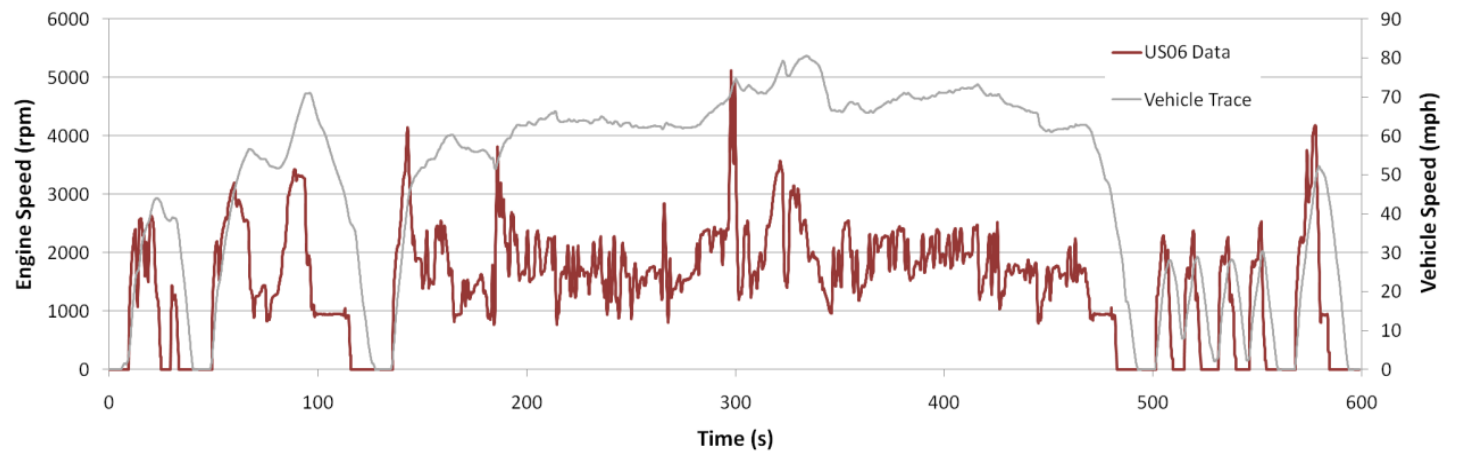

Figure 14: US06 Cycle Engine Speed

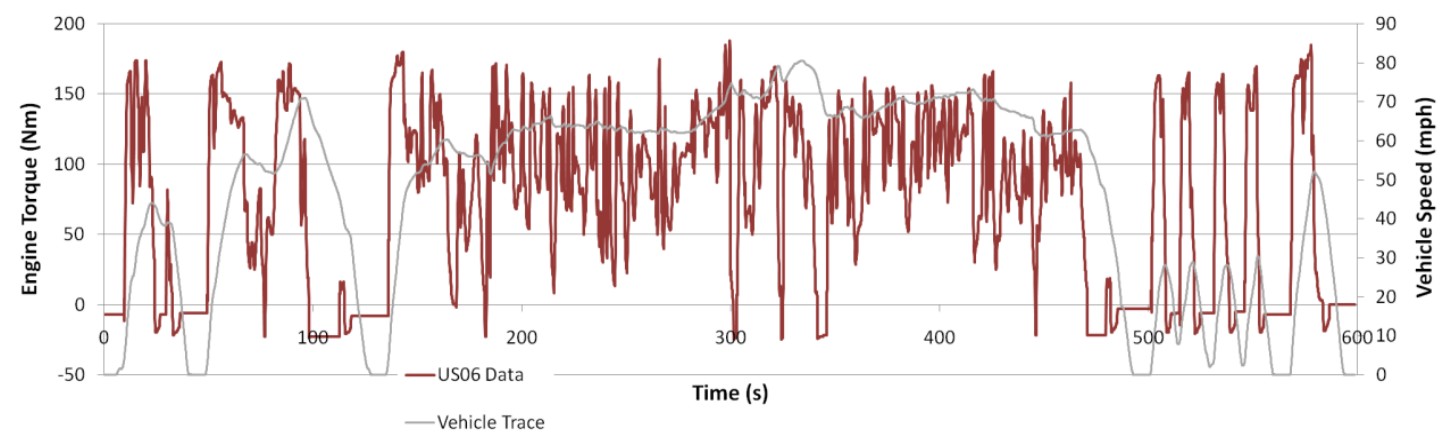

Figure 15: US06 Cycle Engine Torque

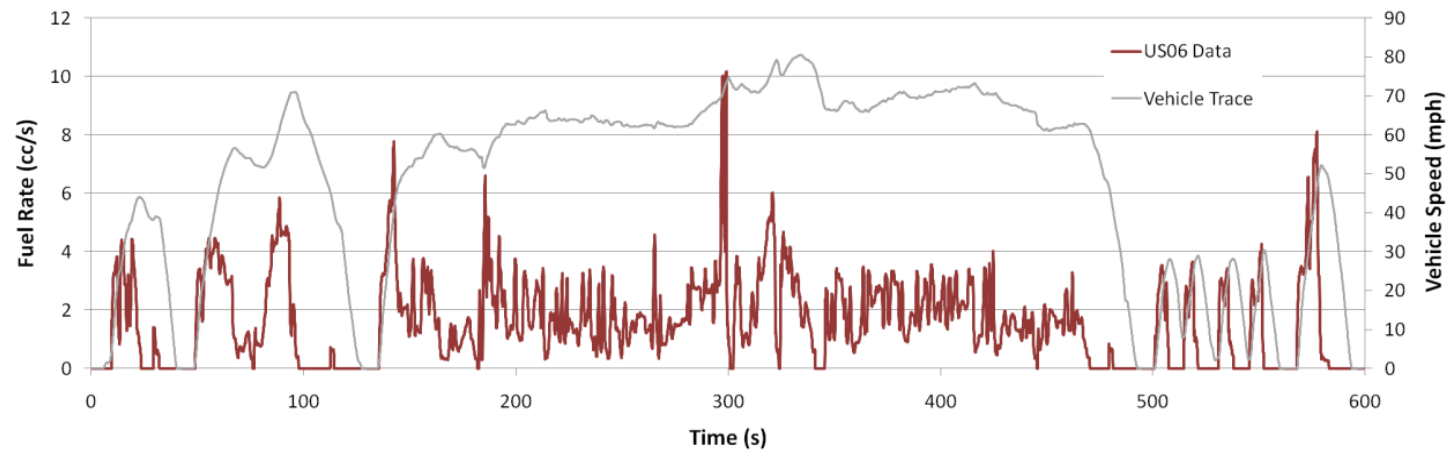

Figure 16: US06 Cycle Fuel Rate

Figure 17 shows a summary plot of the basic engine on/off strategy over the US06 cycle. As would be expected for this more aggressive cycle, engine-off operation is limited primarily to vehicle decelerations. 


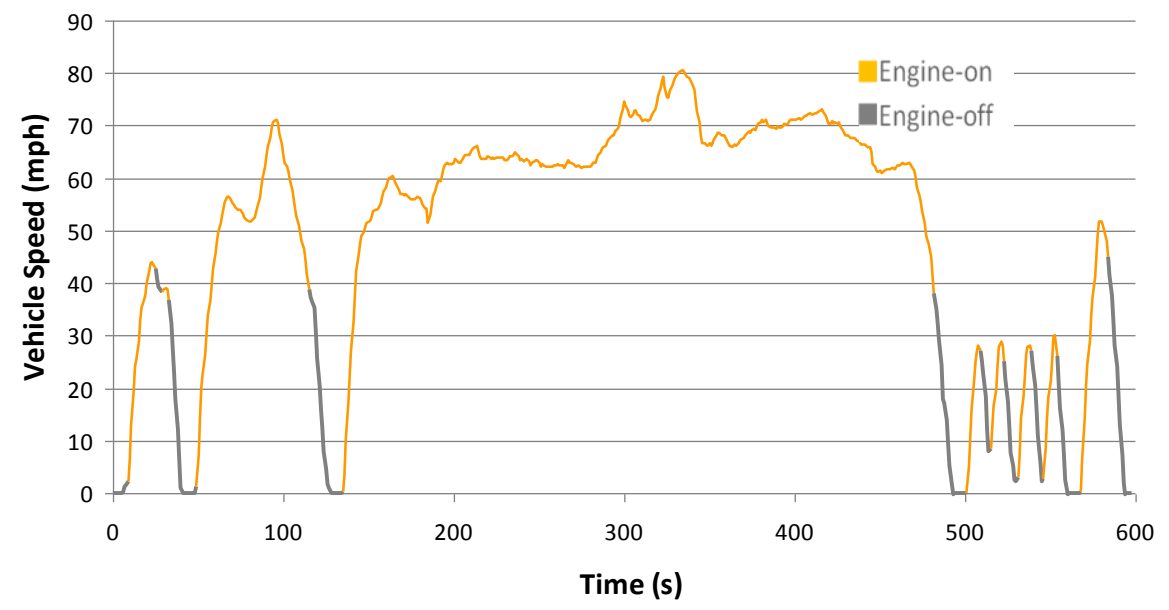

Figure 17: US06 Engine On/Off Strategy Summary

\subsection{High Voltage Battery Usage}

Battery usage over the US06 cycle displays quite a bit of battery assistance and overall shows a higher peak positive and negative power as compared to the other cycles.

Table 7 summarizes the observed peak battery power.

Table 7: US06 Peak Battery Power

\begin{tabular}{|l|c|}
\hline & US06 Cycle \\
\hline Peak Positive Battery Power (kW) & 25.7 \\
\hline Peak Regen Battery Power (kW) & -25.1 \\
\hline
\end{tabular}

More detailed information regarding the battery power and state-of-charge is shown in Figures 18 and 19. As mentioned previously, battery power varies much more under these more aggressive conditions. Despite this higher range of power use, maximum SOC swing during the US06 cycle is roughly $12 \%$ which is similar to the swing observed during Warm Urban operation.

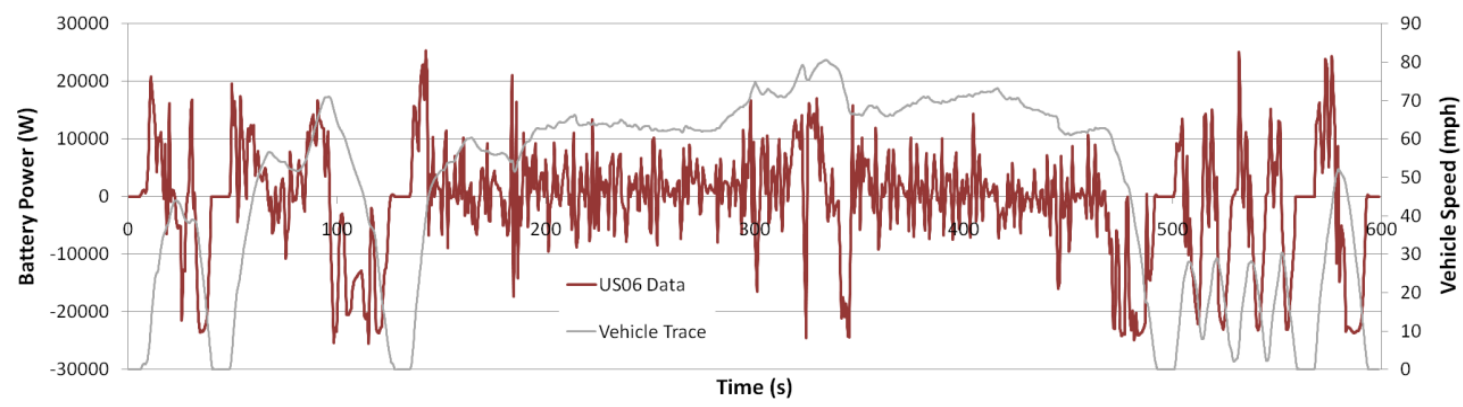

Figure 18: US06 Cycle Battery Power 


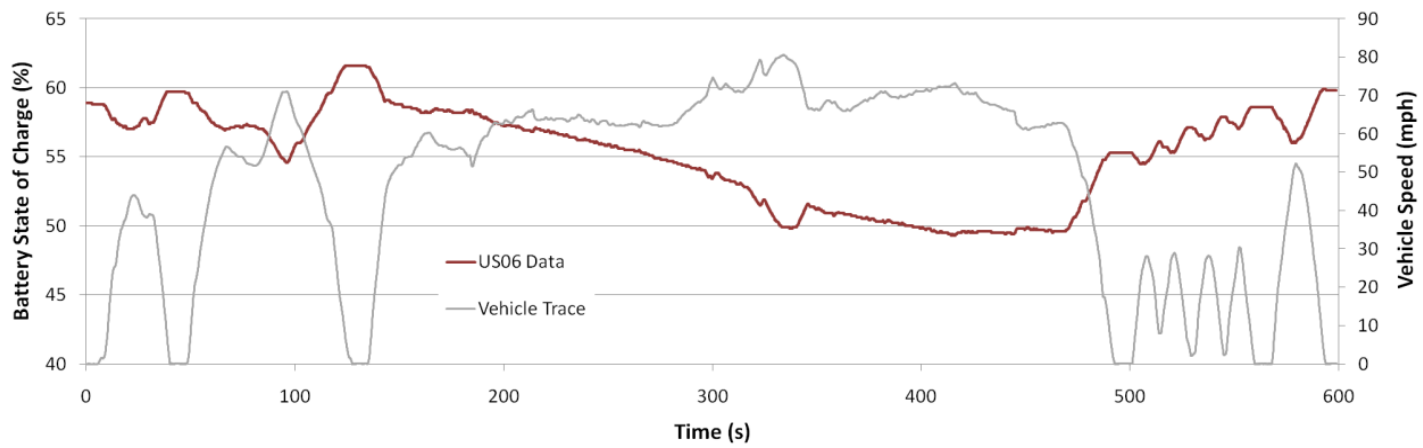

Figure 19: USO6 Cycle State of Charge

\section{Other Operation}

In addition to operation over regulatory cycles, this analysis also provides insight regarding the Fusion Hybrid's operation over repeated accelerations and its operating differences while using air conditioning on the Urban cycle.

\subsection{Repeated Accelerations}

For this testing, 10 back-to-back aggressive accelerations were run to assess performance fade, the degradation of performance over repeated runs. Hybrid vehicles typically scale back performance after a certain number of runs due to battery issues relating to state-of-charge management or thermal management. Figure 20 shows the battery power and vehicle speed over repeated performance cycles for the Fusion. From this plot, it can be see that performance stays fairly constant for the first 7 cycles, this consistent performance is due to minimal de-rating of positive battery power. Following the $7^{\text {th }}$ acceleration, the positive battery power and thus electric performance assist, begins to be de-rated. Following the $5^{\text {th }}$ acceleration, regenerative power during the deceleration back to zero mph begins to reduce and the energy captured is minimal.

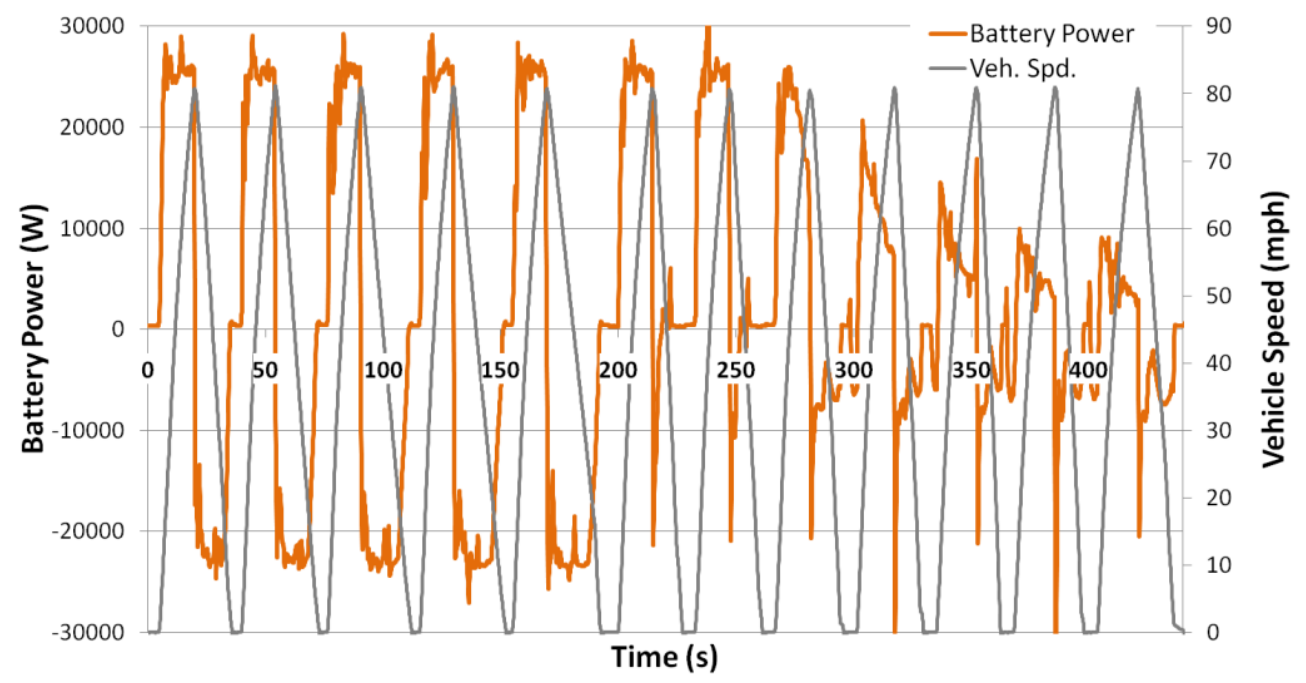

Figure 20: Battery Usage for Repeated Accelerations 
As mentioned previously, the observed performance fade during these repeated accelerations is typically due to battery management related issues. Figure 21 shows the battery temperature and SOC during the repeated accelerations. During the first five cycles, it can be seen that SOC remains fairly constant, whereas battery temperature increases consistently during each acceleration/deceleration cycle. Once the de-rating of regenerative energy capture occurs following the fifth cycle, the battery SOC drops fairly quickly. Given the minimal SOC change over the first five cycles, the battery power de-rating observed for this scenario appears to be battery temperature related.

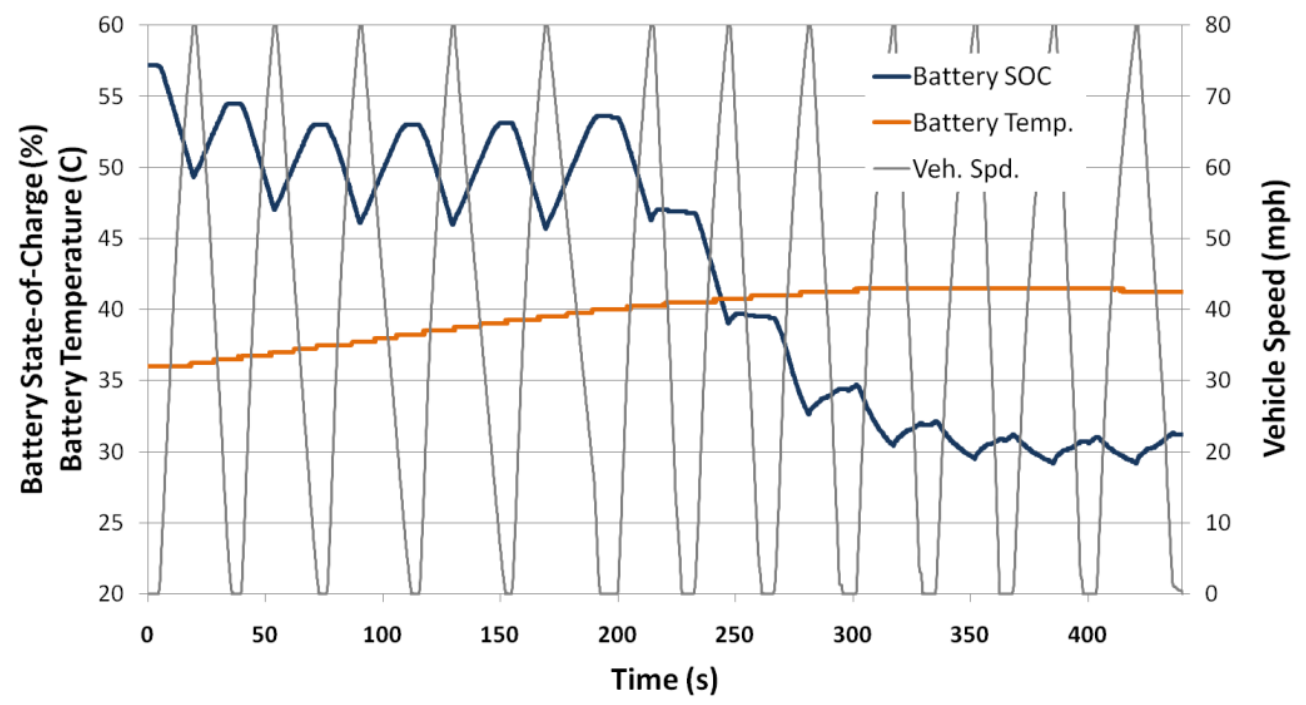

Figure 21: Battery Temperature and SOC over Repeated Accelerations

\subsection{Impact of Air Conditioning}

In order assess one facet related to the real-world fuel economy of the Ford Fusion, tests were done at elevated test-cell temperatures with the air-conditioning system running and the climate control system set to $72 \mathrm{~F}$. For this testing, the test-cell temperature was raised to $95 \mathrm{~F}$ and the Urban and Highway tests were run for a comparative basis to the previously discussed runs without air-conditioning. While air conditioning tests frequently include an additional solar load, this additional load was not included due to test-cell capability limitations. Using the Urban and Highway test results, Figure 22 below shows the sizeable impact air-conditioning operation has on vehicle fuel economy. It is worth noting that this number will vary significantly depending on outside temperature and humidity as well as vehicle temperature settings, but these results do help illustrate the large impact air conditioning has on fuel economy. 


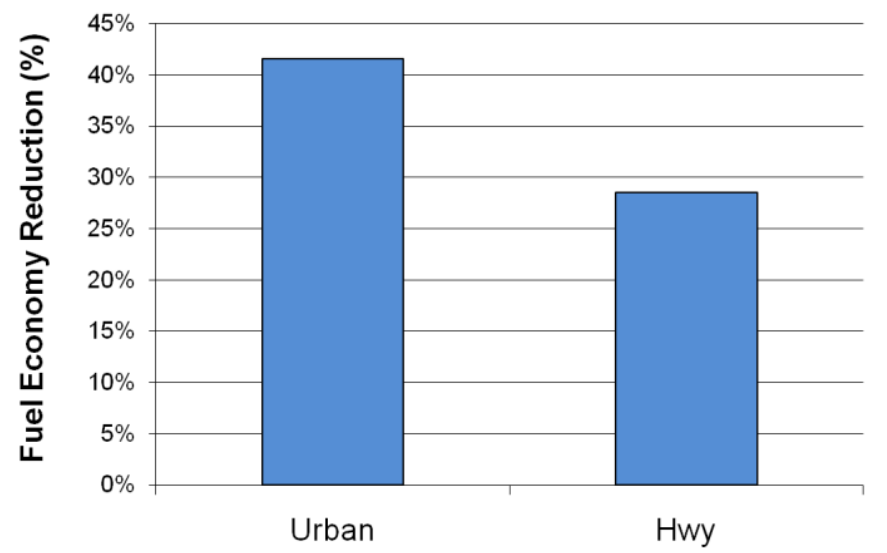

Figure 22: Fuel Economy Impact of Air-Conditioning

It is also interesting to note how the vehicle operates differently over the Urban and Highway cycles given the additional air-conditioning load. More specifically, the Urban sees a sizable decrease in engine-off operation with air-conditioning operation, whereas the Highway cycle encounters essentially no impact in the fraction of engine-off operation. Figure 23 below illustrates this observation.

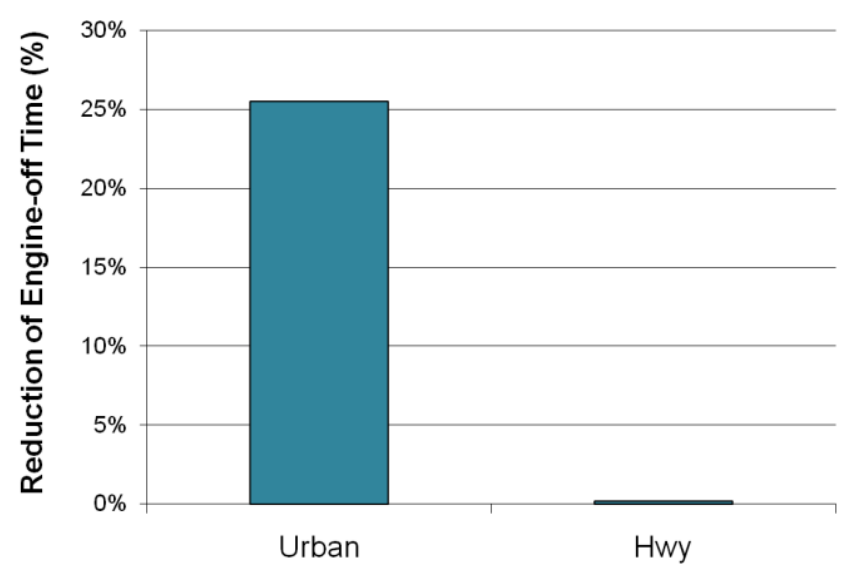

Figure 23: Engine-off Impact of Air-Conditioning

When looking at the data in more detail, two different effects can be observed due to the additional load of the air conditioning. While engine-off operation during the urban cycle still takes place, the total fraction of engine-off operation is reduced by about $25 \%$. This reduction in operation occurs primarily when the vehicle would normally propel the vehicle with the engine off. In contrast, engine-off operation during vehicle deceleration remains active. Figure 24 below shows a section of the Urban cycle for the with and without air-conditioning runs. In this figure, engine-off behavior can be seen to occur for both cases, but the additional air conditioning load results in reduced engine-off operation as well as delayed engine-off operation during tip-outs and decelerations. 


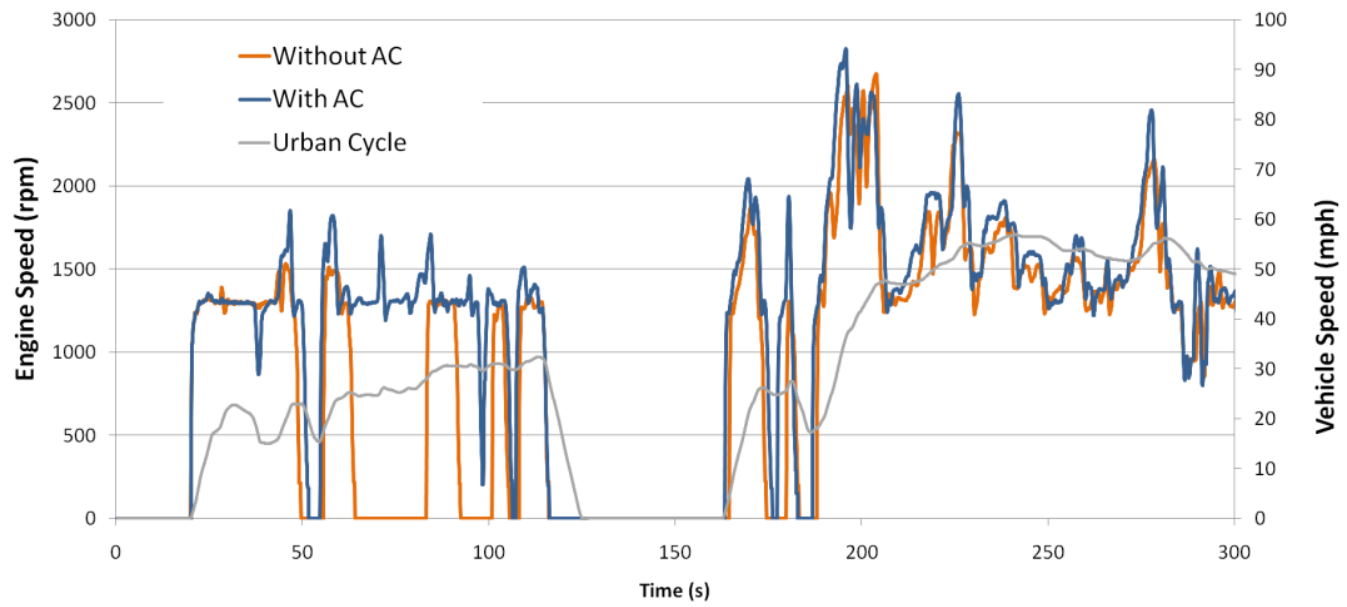

Figure 24: Urban Cycle Engine Speed with and without Air conditioning

The second effect due to the additional load of the air conditioner is that the total engine power used is higher. As would be expected, the additional load of the air conditioner must be accommodated by running the engine at a higher operation power. While the high-voltage air conditioning system can be powered from the battery, this energy ultimately needs to be created using the engine in order to remain roughly charge sustaining. Figure 25 shows the engine power for both with and without a/c while operating over a segment of the Highway cycle. As discussed previously, engine-off operation remains nearly identical, but engine power is much higher due to the additional load of the air conditioner.

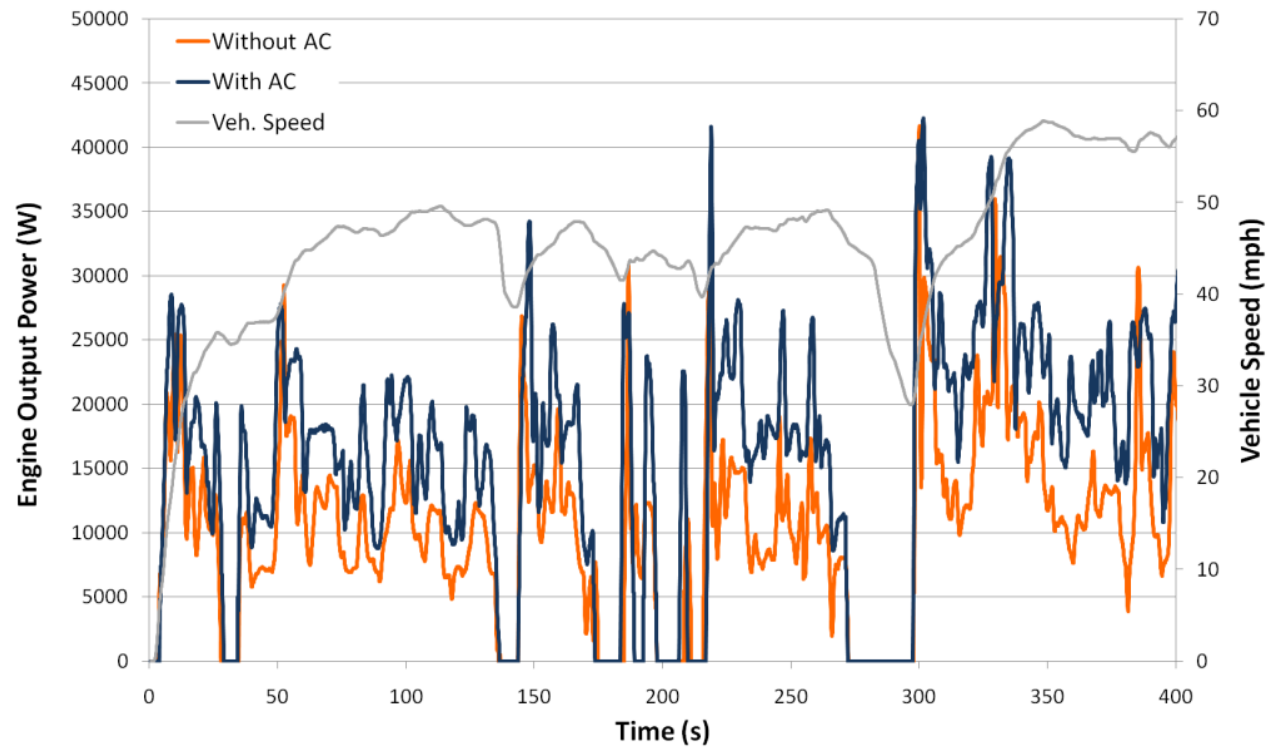

Figure 25: Highway Engine Power with and without Air conditioning 


\section{Preliminary Component Assessment}

Utilizing the data collected over the Urban, Highway, and US06 cycles, specific components of the Fusion's hybrid system can be evaluated in greater detail. More specifically, data accessed from the vehicle's CAN data bus may be used to better understand the general operation of particular components within the hybrid system. While CAN data is not always perfectly accurate, it is typically a reasonable source of data for high-level assessment of component operation. Additionally, CAN data often allows for information that would otherwise not be available to be accessed and collected during testing. The following sections seek to discuss some of the major hybrid system components in greater detail.

\subsection{Engine Operation and Usage}

As discussed previously, the Fusion uses a relatively large 2.5L Atkinson cycle engine to provide vehicle power. Given the fairly large size and peak power of this engine, it is expected that the engine spends a fair amount of time at lower relative speeds. To illustrate this point, Figure 26 below shows the Fusion's engine speed and load usage over the Urban, Highway, and US06 cycles. As expected, the vehicle spends a significant fraction of engine operating time between 1000 and $1750 \mathrm{rpm}$.

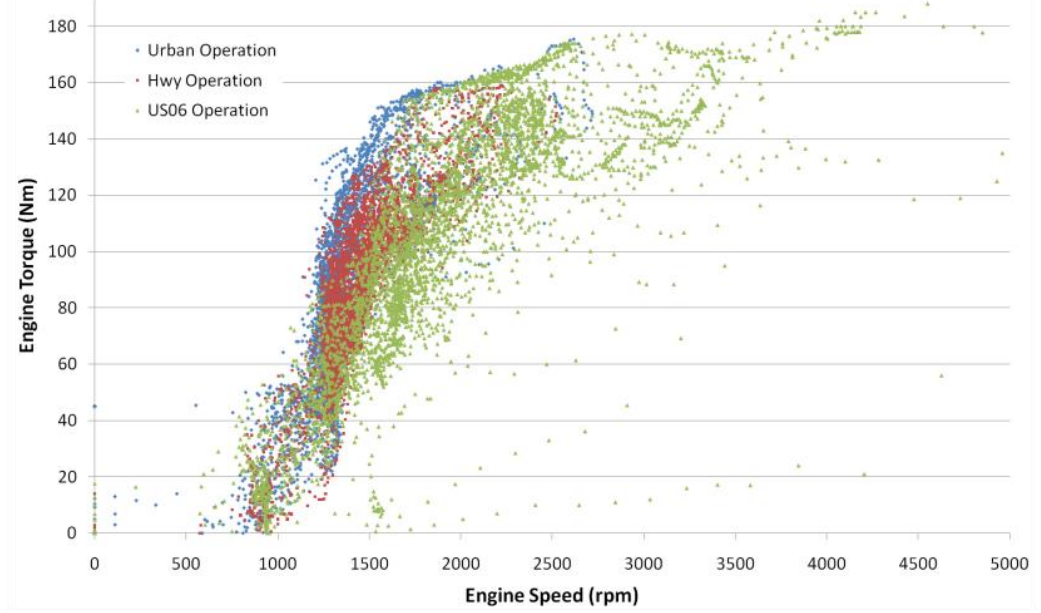

Figure 26: Engine Usage Scatter over Urban, Highway and US06 Cycle

As can be seen in the previous figure, the engine follows a fairly narrow bandwidth in the torque/speed envelope of possible operation. Similar to other power-split type hybrid vehicles, this usage pattern shows the vehicle working to balance running at optimal efficiency (higher loads) versus running the vehicle to meet road-load demand with some hybrid system buffering. In fact, the centroid of the maximum integrated fuel usage relative to engine power is roughly $10 \mathrm{~kW}(1250 \mathrm{rpm}, 80 \mathrm{Nm})$ which is approximately 9 percent of the maximum 116kW (156HP) rated engine power. This behavior would be anticipated given the relative low power requirements of the Urban and Highway cycles in addition to the moderate-to-high power requirements of the US06 cycle. The higher power area of additional fuel usage near $2500 \mathrm{rpm} / 140 \mathrm{Nm}$ is likely a major operating region for the higher power portions of the US06 cycle. 
To further exemplify this engine operating dynamic, Figure 27 shows a histogram of the fraction of non-zero engine operation relative to engine power and vehicle power for the Urban, Highway, and US06 cycles. As can be seen in the figure, the majority of vehicle operation occurs at fairly low engine and vehicle power levels. Moreover, at low tractive power requirements, the average engine load is quite a bit higher than the required tractive power. This represents the Fusion's ability to operate the engine efficiently even at low power requirements by charging the hybrid battery and using this energy later for EV driving or electric-assist. Once the tractive power required begins to increase, the engine operation moves closer to a more load-following strategy in which engine power more closely matches tractive power.

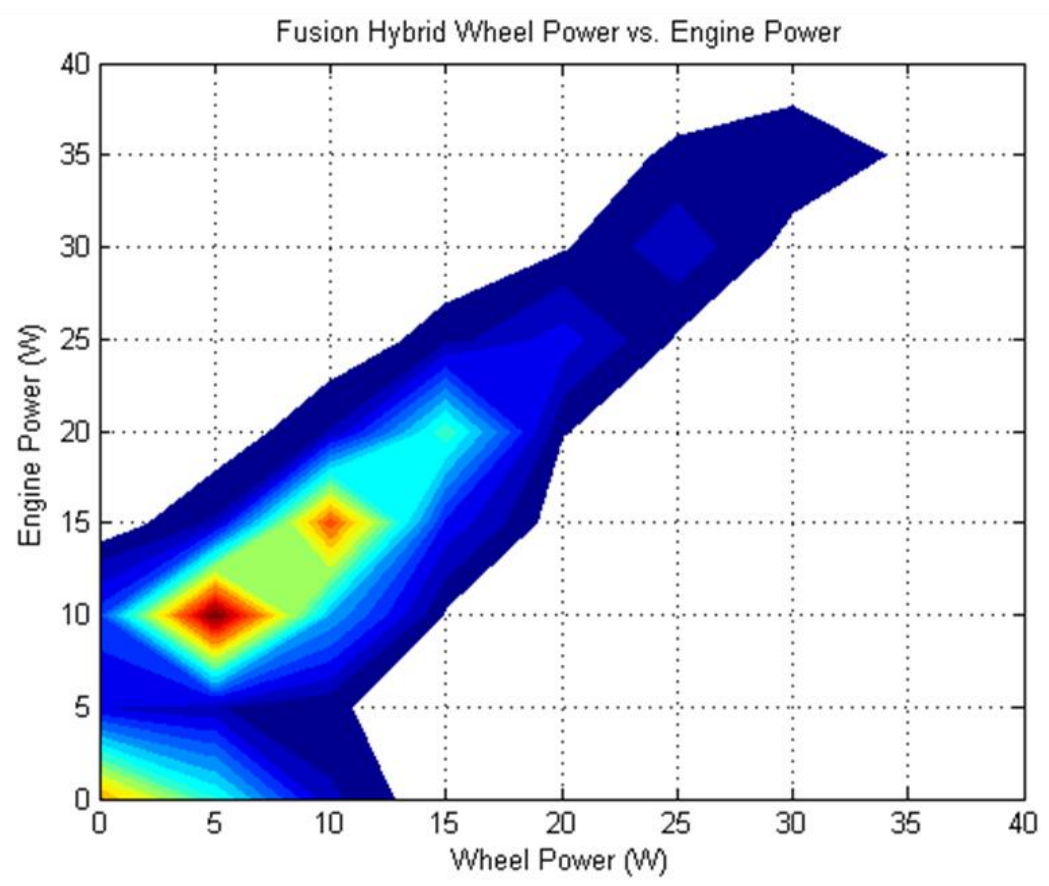

Figure 27: Engine Power versus Wheel Power Histogram over Urban, Highway, and USO6 Cycle

\subsection{Electric Machine Operation}

In addition to information regarding engine operation, CAN data-bus information is also available for both electric machines. The available information for each motor was operating speed and torque. This information aids in understanding the operating envelope for the electric machines over the standard cycles as well as during aggressive accelerations. Figure 28 shows the operation of the primary motor (Motor B) over the three cycles used for analysis in this report (note: this motor also operates as a generator during regeneration events). The motor sees a wide range of operating speeds, including high speed operation near 10,000 rpm. 


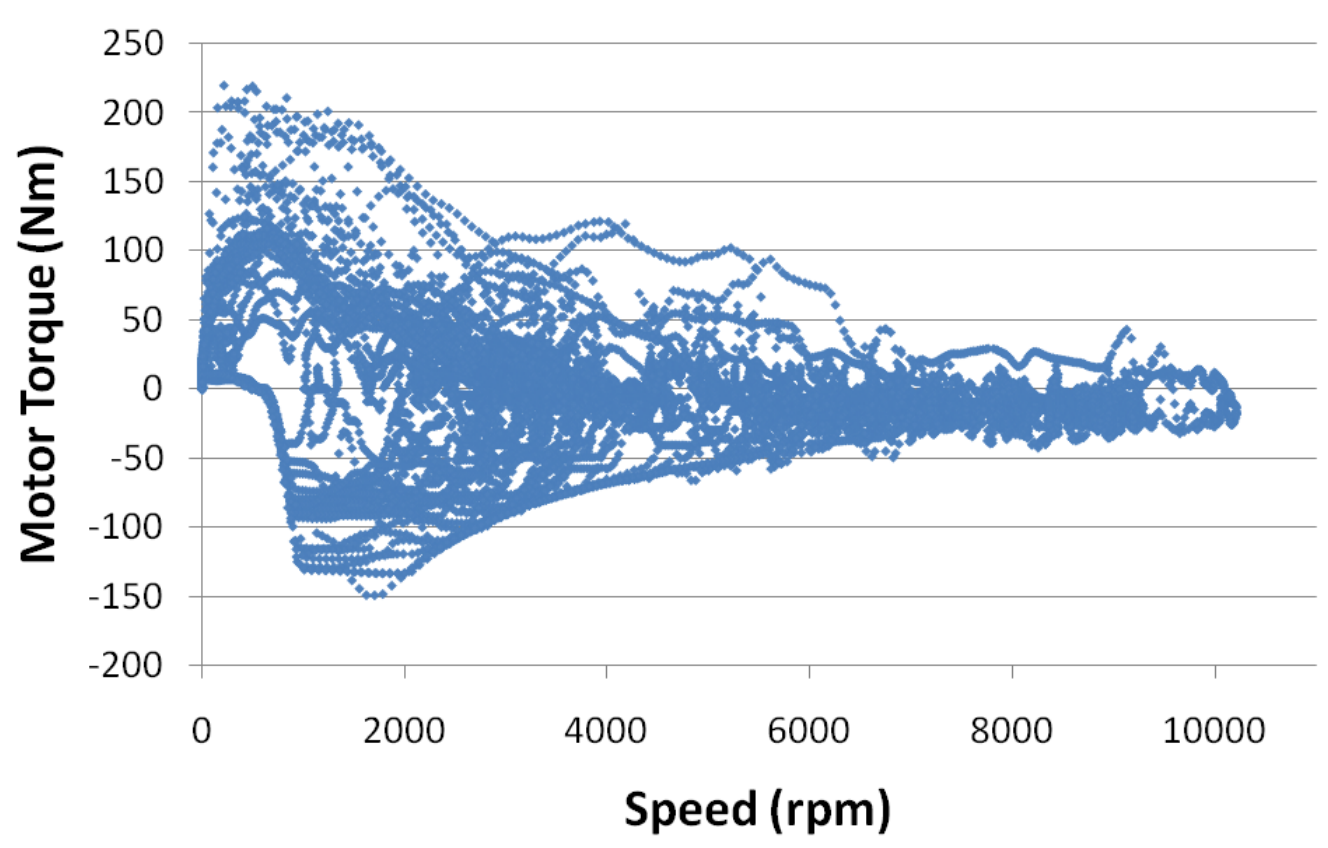

Figure 28: Traction Motor Operation over Urban, Highway, and US06 cycles

Figure 29 shows similar operating envelope information for the primary generator (note: the generator also functions as a motor, providing torque, in certain situations). As can be seen in the figure below, the generator sees operation in all four quadrants, but predominantly the third and fourth.

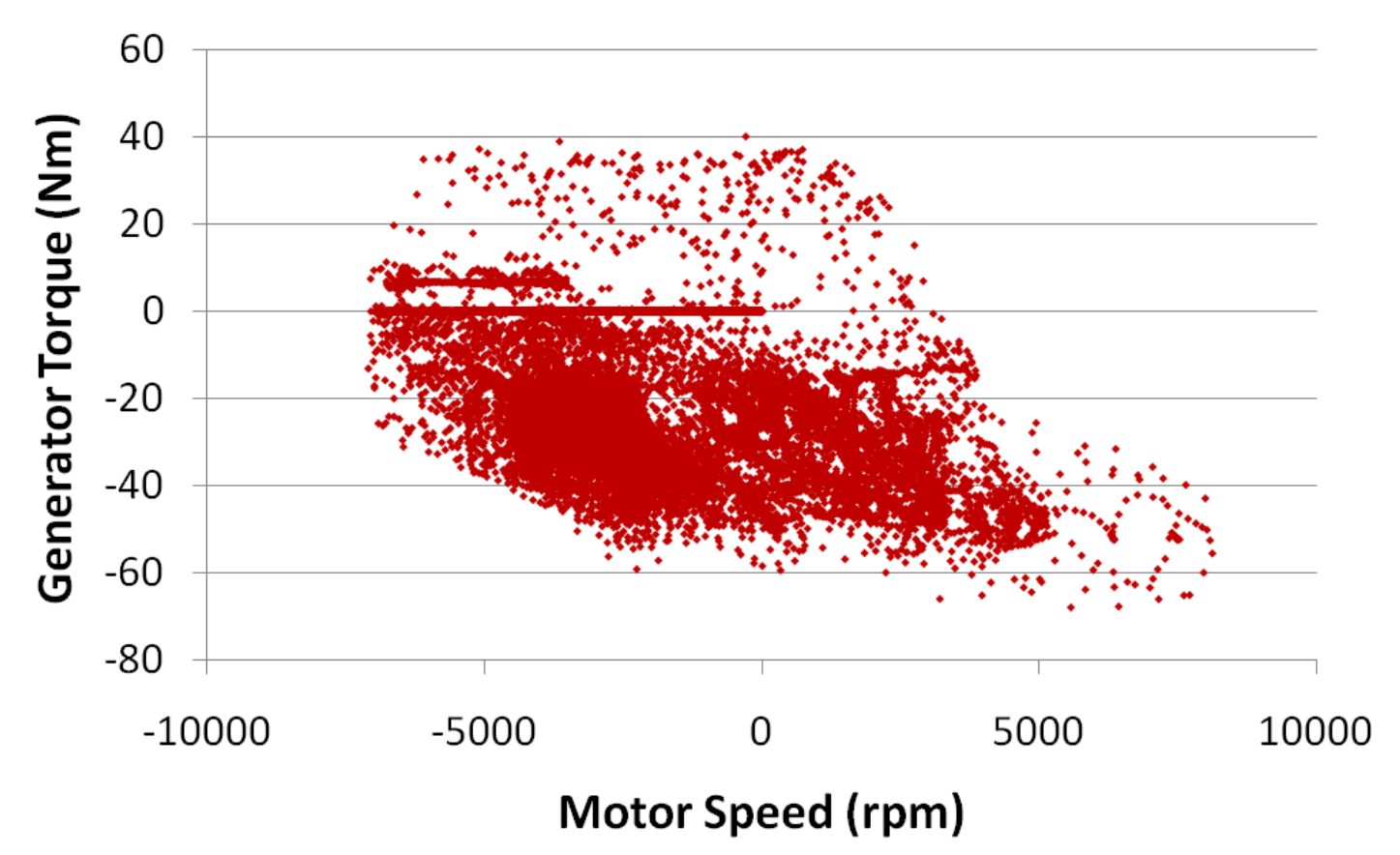

Figure 29: Generator Operation over Urban, Highway, and US06 cycles 
In addition to the general operating usage during standard operation, it is also useful to evaluate the main traction motor's maximum capability over a range of speeds. During the aggressive acceleration testing, the motor works to provide additional tractive effort and thus the motor operation during these maneuvers is useful to understand the peak motor capability. Figure 30 shows the motor operation during the repeated accelerations discussed previously in this report. To help contrast the motor usage during more standard operation to the maximum observed capability, the motor usage over the standard test cycles has also been included in Figure 30.

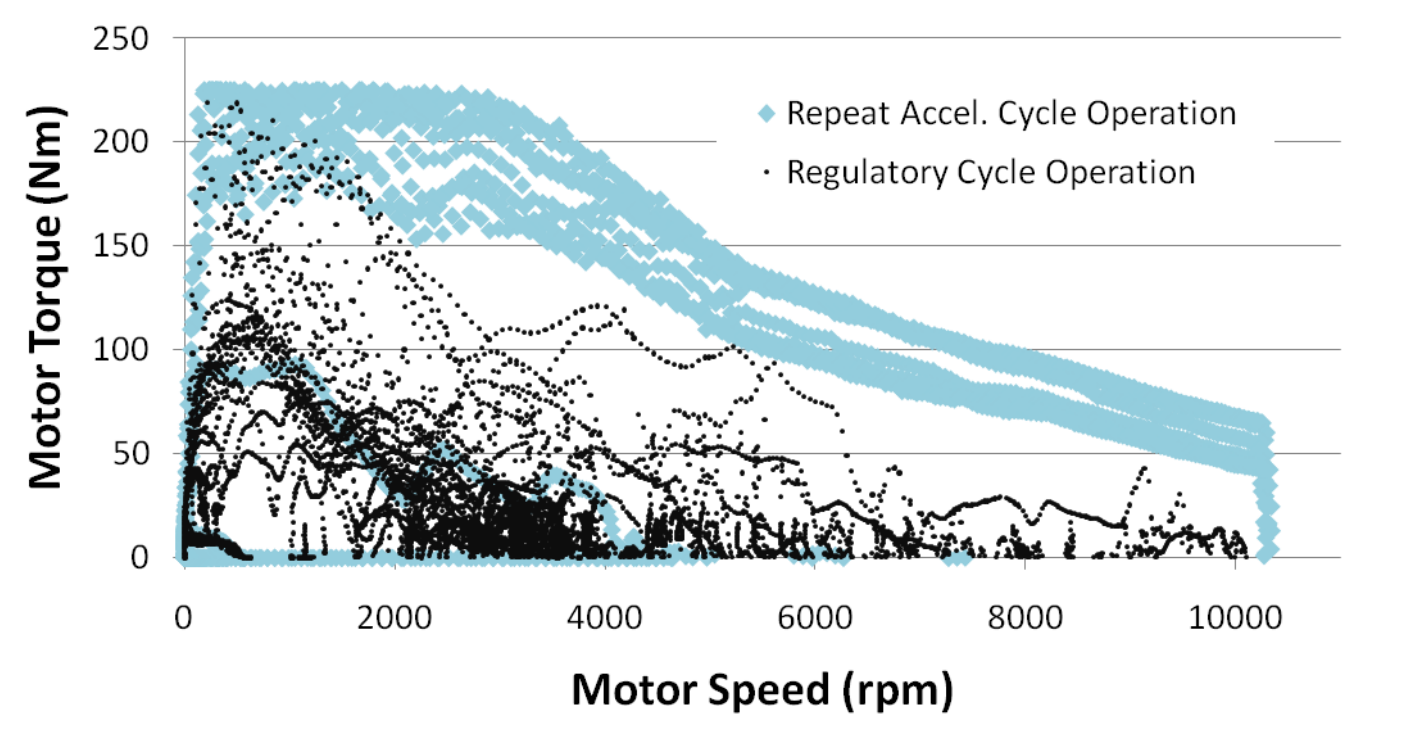

Figure 30: Maximum and Typical Traction Motor Usage

\subsection{Voltage Boost Operation}

An additional noteworthy component included in the Fusion hybrid system is a battery voltage boost converter. Referred to by Ford as a Variable Voltage Converter, this component increases the voltage seen by the electric machines under certain scenarios when more power, and thus voltage is needed. By avoiding the losses incurred at higher operating voltages when they are not needed, the system allows for improved system efficiency while retaining a high level of electric capability. Fortunately, CAN data that appears to be the voltage level seen by the electric machines was available. Table 8 shows the proportion of each cycle that was run using the voltage boost. As would be expected for the lower power Urban and Highway cycles, the voltage boost is rarely used. In contrast, the higher power and much higher maximum speed US06 cycle shows a considerable amount of voltage boost operation.

Table 8: Voltage Boost Fraction for Standard Cycles

\begin{tabular}{|c|c|}
\hline Cycle & Percent of Cycle with Boosting \\
\hline Urban & $<1$ \\
\hline Hwy & $<1$ \\
\hline US06 & 41 \\
\hline
\end{tabular}


In addition to the use of the boost converter during high power maneuvers, the boost converter is also used for scenarios that have high motor speeds. Such is the case in Figure 31 below. Although the actual motor power is fairly low due to the engine primarily powering the vehicle, the voltage boost is quite active during the highest speed portion of the US06.

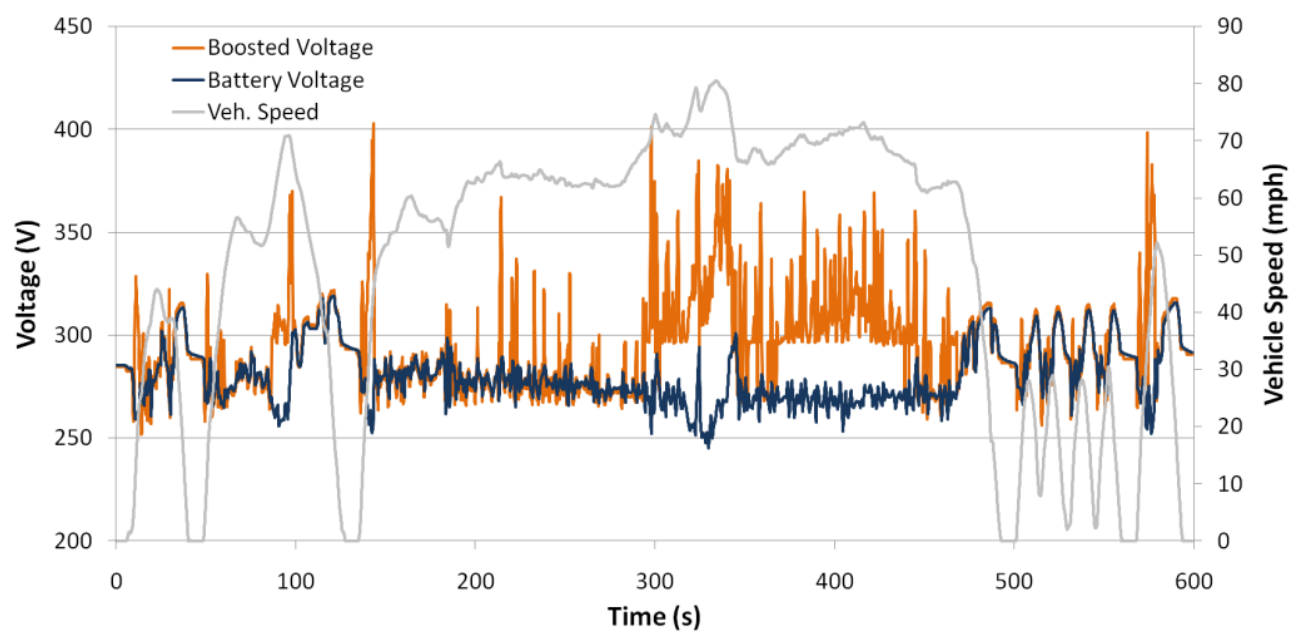

Figure 31: US06 Battery Voltage and CAN Boosted Voltage Signal

To emphasize the usage of the boost converter in relation to the operating envelopes of the electric machines, Figure 32 shows the boosted operation for both electric machines while operating over the US06 cycle. From these figures, it can be seen that the boosting for the primary motor is not always used for peak motor power. In contrast, the primary generator does operate near the peak of its operating envelope while running using the voltage boost.
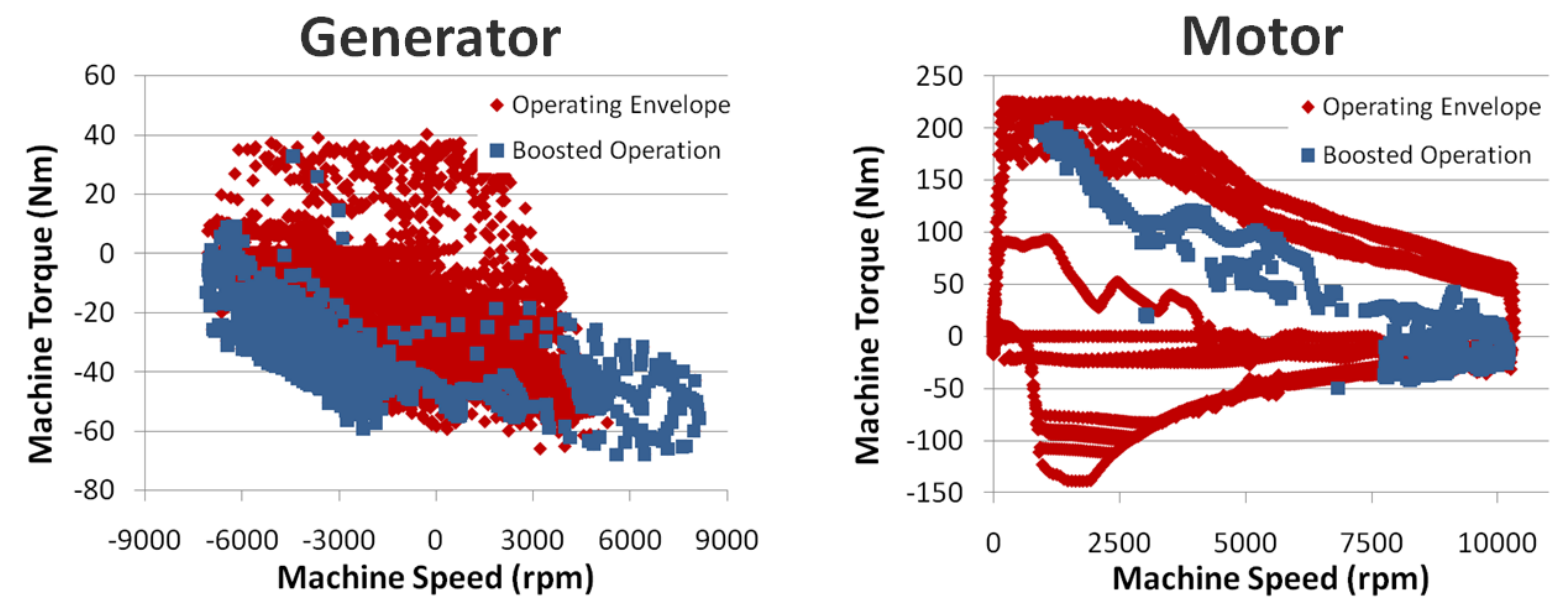

Figure 32: Electric Machine Boosted Operation and Operating Envelope

In addition to the significant amount of voltage boosting seen while operating over the US06 cycle, the voltage boost also sees significant use during repeated accelerations. In this case, the traction motor operates entirely along the peak usage curve when operating in boosted mode, i.e. the boosting is for power and thus acceleration reasons. 
From Figure 33 below, it can be seen that the voltage boost begins near the initial vehicle acceleration and continues boosting voltage into the high speed brake regeneration during deceleration.

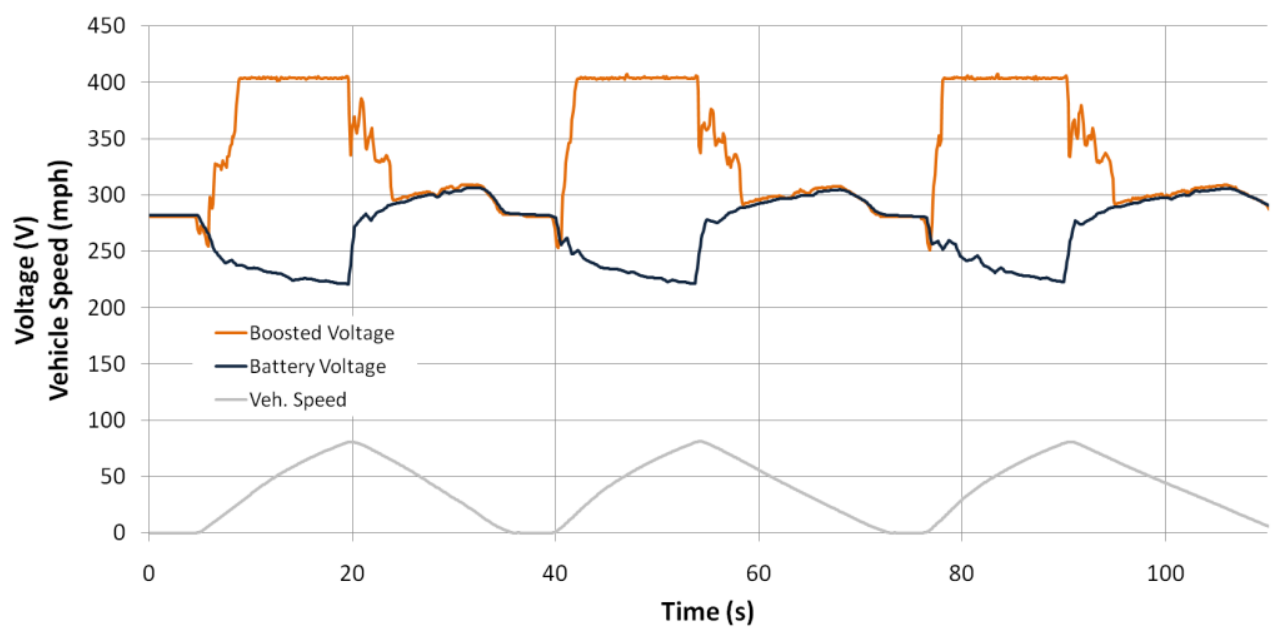

Figure 33: Battery and Boosted Voltage During Accelerations

\section{Battery Pack Operation}

Given the high fidelity voltage and current measurements taken during vehicle operation, a basic characterization of the Fusion's battery pack can be made. By plotting the measured high-voltage battery voltage versus the measured current and plotting a best fit line, some basic battery characteristics can be estimated. Figure 34 shows the voltage versus current plot for the Fusion over the Urban cycles. Operation over the Highway and US06 cycles is very similar and has been omitted. Observing the slope and offset of the best-fit line, the Fusion's battery pack has an observed resistance of roughly $0.4 \mathrm{Ohms}$ and a nominal pack voltage of 280 Volts. It should be noted that the spread observed from the best-fit line represents dynamics other than the basic Voltage $=$ Current $x$ Resistance relationship. Although more accurate, dynamic estimates are possible they will likely be very close to the basic estimates shown in Figure 34 for most operating scenarios at a similar state of charge.

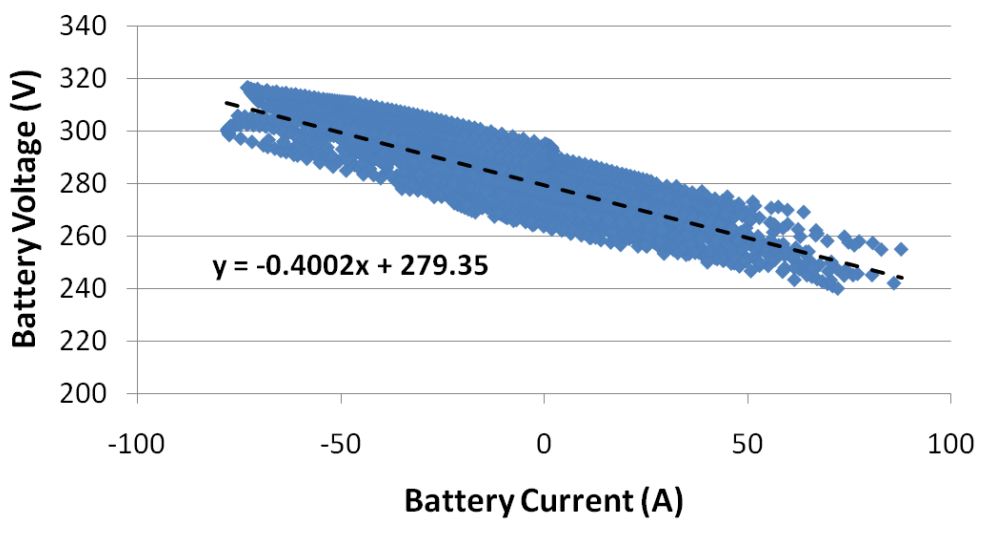

Figure 34: Battery Voltage versus Current 


\section{Conclusions and Future Work}

Vehicle-level testing supplemented with decoded vehicle CAN bus information has provided significant insight into the operating strategies and behavior of the Ford Fusion Hybrid as well as some of its important hybrid components. The MY2010 Fusion achieves high fuel economy over a wide range of operation and while seeking to provide improved drivability and performance. Relevant findings include:

- Significant engine-off operation, including the ability to operate in engine-off mode at speeds up to roughly $47 \mathrm{mph}$.

- Reduced fuel economy penalty between warm and cold Urban operation due to a shortened 200s vehicle warm-up period and significant engine-off operation.

- Engine-off operation during high-speed vehicle braking due to higher EV capability.

- Vehicle shows minimal performance degradation over 7 repeated 0-80mph accelerations, but begins to reduce electric assist afterwards.

- Significant decrease in fuel economy while operating the air conditioning for both the Urban and Highway cycles, but different vehicle behavior in response to the air-conditioning load depending on driving style.

- Improved understanding of the operating envelope and usage for both the engine and the electric machines.

- Significant voltage boosting for both increased motor power as well as high speed motor operation.

Detailed data regarding this vehicle as well as additional AVTA vehicles may be found in ANL's Downloadable Dynamometer Database $\left(D^{3}\right)$ at https://webapps.anl.gov/vehicle data/. 


\section{Argonne}

\section{Energy Systems Division}

Argonne National Laboratory

9700 South Cass Avenue, Bldg. 362

Argonne, IL 60439-4815

www.anl.gov

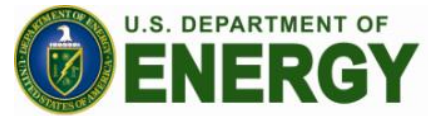

Argonne National Laboratory is a U.S. Department of Energy laboratory managed by UChicago Argonne, LLC 